\title{
Feeling well and talking about sex: psycho-social predictors of sexual functioning after cancer
}

\author{
Janette Perz ${ }^{*}$, Jane M Ussher, Emilee Gilbert and The Australian Cancer and Sexuality Study Team
}

\begin{abstract}
Background: Changes to sexual wellbeing are acknowledged to be a long-term negative consequence of cancer and cancer treatment. These changes can have a negative effect on psychological well-being, quality of life and couple relationships. Whilst previous conclusions are based on univariate analysis, multivariate research can facilitate examination of the complex interaction between sexual function and psycho-social variables such as psychological wellbeing, quality of life, and relationship satisfaction and communication in the context of cancer, the aim of the present study.

Method: Six hundred and fifty seven people with cancer (535 women, 122 men) and 148 partners (87 women, 61 men), across a range of sexual and non-sexual cancers, completed a survey consisting of standardized measures of sexual functioning, depression and anxiety, quality of life, relationship satisfaction, dyadic sexual communication, and self-silencing, as well as ratings of the importance of sex to life and relationships.

Results: Men and women participants, reported reductions in sexual functioning after cancer across cancer type, for both people with cancer and partners. Multiple regression analysis examined psycho-social predictors of sexual functioning. Physical quality of life was a predictor for men and women with cancer, and for male partners. Dyadic sexual communication was a predictor for women with cancer, and for men and women partners. Mental quality of life and depression were also predictors for women with cancer, and the lower self-sacrifice subscale of self-silencing a predictor for men with cancer.
\end{abstract}

Conclusion: These results suggest that information and supportive interventions developed to alleviate sexual difficulties and facilitate sexual renegotiation should be offered to men and women with both sexual and non-sexual cancers, rather than primarily focused on individuals with sexual and reproductive cancers, as is the case currently. It is also important to include partners in supportive interventions. Interventions aimed at improving sexual functioning should include elements aimed at improving physical quality of life and sexual communication, with a focus on psychological wellbeing also being important for women with cancer.

Keywords: Cancer and sexuality, Psycho-social predictors, Sexual functioning, Quality of life, Communication

\section{Background}

\section{Disruptions to sexuality after cancer}

It is now widely recognized that cancer and its treatment can have a significant effect on the quality of life of both people with cancer and their family members, in particular their intimate partner [1]. Sexuality and intimacy are important aspects of an individual's quality of life $[2,3]$, and there is a growing body of evidence to show that cancer can result in dramatic changes to sexuality,

\footnotetext{
*Correspondence: j.perz@uws.edu.au

Centre for Health Research, University of Western Sydney, Locked Bag 1797, Penrith South 2751, Australia
}

sexual functioning, relationships, and sense of self. These changes can be experienced as the most important in the person with cancer's life $[4,5]$, with the impact lasting for many years after treatment [6,7], often resulting in significant physical and emotional side-effects [8-10].

Sexual difficulties following cancer are primarily the result of the effects of cancer treatments, rather than the disease itself $[11,12]$. For women, the focus of research has been on the impact of treatments for gynecological or breast cancers, which can result in anatomical changes, such as vaginal shortening or reduced vaginal elasticity [13], pelvic nerve damage, clitoris removal, vaginal stenosis,

\section{Biomed Central}

(c) 2014 Perz et al.; licensee BioMed Central Ltd. This is an Open Access article distributed under the terms of the Creative Commons Attribution License (http://creativecommons.org/licenses/by/2.0), which permits unrestricted use, distribution, and reproduction in any medium, provided the original work is properly credited. The Creative Commons Public Domain Dedication waiver (http://creativecommons.org/publicdomain/zero/1.0/) applies to the data made available in this article, unless otherwise stated. 
and fistula formation [14]; and physical changes, such as decreased bodily function [14], fatigue [15], dyspareunia [16], vaginal dryness [17], infertility [18], and post-coital vaginal bleeding [19]. Negative body image or feelings of sexual un-attractiveness [6,20], concern about weight gain or loss [21], loss of femininity [22], as well as alterations to the sexual self [23], can exacerbate the impact of these physical changes. In combination, this can result in changes to women's response [18], including changes to: desire $[18,24]$, orgasm [21,25], arousal [26], vaginal lubrication [15,17], genital swelling [16] and genital sensitivity [27], leading to decreased frequency of sex [28], and lack of sexual pleasure or satisfaction [29,30].

Research examining men's sexuality post-cancer has primarily focused on prostate and testicular cancers [31-33]. For example, men with prostate cancer have reported that hormone therapy is like 'chemical castration' [34], resulting in erectile dysfunction [35,36], diminished genital size, weight gain, urinary incontinence and bodily feminization [37-39]. Other treatments reportedly result in loss of sexual desire [40], reduced erotic dreams and sexual fantasies [37], decreased orgasmic sensation, and bowel and urinary incontinence [31]. Similarly, following surgery for testicular cancer, men have reported reductions in sexual functioning and enjoyment, fertility concerns, as well as negative body image [41-44]. Rectal cancer has also been associated with reductions in sexual functioning, for both women and men $[45,46]$.

There is some evidence that individuals with colorectal [47-49], colon [50], head and neck [51,52], bladder [53], lymphatic [54,55] and lung [56] cancers can also experience a reduction in sexual interest and sexual activity, changes to body image and feelings of sexual competency, as well as sexual dysfunction, and alterations to sexual self-esteem [50,57,58]. Adult survivors of childhood cancer, across a range of cancer types and treatments, have also been shown to report sexual difficulties and concerns $[59,60]$. However, previous research on sexual changes after cancer has primarily focused on cancers that directly affect the sexual or reproductive organs, with each study examining a single cancer type, precluding comparison across sexual and non-sexual cancers. The present study will address this imbalance in the research literature through examining changes in sexual functioning and sexual satisfaction, for both women and men, across a range of cancer types, both sexual and non-sexual.

\section{Pathways to sexual difficulty and distress after cancer}

There is a growing body of research examining the association between sexual changes experienced after cancer and quality of life or psychological wellbeing $[10,36,47,48,58,61]$, suggesting that sexual difficulties are associated with lower quality of life, and higher levels of distress. For example, sexual changes have been found to be associated with reduced quality of life or psychological distress in men with prostate cancer [10,36,40,62-64], rare cancers [58], lymphoma [65,66], and colorectal cancer [47]. For women, sexual difficulties have been associated with reduced quality of life or distress in the context of breast cancer $[17,67,68]$, cervical cancer $[20,61,69-71]$, and colorectal cancer $[47,48]$. Other studies have measured sexual functioning and quality of life as independent outcome variables, but have not examined the relationship between the two [72-75].

A number of factors have been examined as possible predictors of sexual difficulties and psychological distress after cancer, primarily focusing on demographic characteristics such as age $[45,47,56,65,76]$, gender $[45,47,48,60]$, ethnicity $[64,77]$, marital status [68], or education [45,78], as well as the influence of treatment type $[45,47,69,73,79]$. Older age $[45,47,65]$, and radiation treatment $[10,61,69,76]$ have been consistently associated with lower levels of sexual functioning, with a number of studies also reporting gender differences in demographic predictors of functioning $[45,47,79]$. However, characteristics of the individual with cancer are not the only predictors of sexual functioning post-diagnosis and treatment. Relationship factors are recognized as having a significant influence on sexual difficulties experienced outside of the cancer context [80], yet the association between relationship factors and sexual adjustment after cancer has been neglected [47]. There is some evidence that quality of the couple relationship is associated with sexual satisfaction and higher levels of sexual functioning [81], and that couples' quality of life and marital satisfaction are linked [36], in the context of cancer. Successful renegotiation of sexual practices after cancer has also been reported to be associated with couple communication, in qualitative research conducted with cancer carers $[82,83]$. Nevertheless, these findings are limited, and are primarily based on univariate analysis. The present study will address this limitation in previous research, through conducting multifactorial research to examine the complex interaction between sexual function and psychological wellbeing, quality of life, and relationship satisfaction and communication, in the context of cancer $[71,84]$.

\section{Relationship communication and context}

There is a dearth of previous research examining the influence of couple communication on sexual functioning for people with cancer. There is, however, evidence that the adoption of an open and responsive pattern of couple communication after cancer is associated with lower levels of distress and higher levels of marital satisfaction $[85,86]$, as well as effective emotion and problem focused coping [87], associated with relationship closeness [88,89]. Conversely, many partners are over-protective towards the person with cancer, engaging in "protective buffering" in an attempt to prevent distress [90,91], or "disengaged 
avoidance" [88], p412, involving complete denial of cancer or its effects. This buffering or avoidance is analogous to the pattern of self-silencing initially identified by Dana Jack [92] as an explanation for women's greater susceptibility to depression. Self-silencing is characterized as the propensity to engage in compulsive caretaking, pleasing the other, and inhibition of self-expression in relationships, in an attempt to achieve intimacy and meet relational needs [93]. Self-silencing is not a pattern of behaviour unique to women. In a number of studies men have been found to report levels of self-silencing equal to those of women [94,95], or higher than women [96-98]. Differences have also been reported between women and men in patterns of self-silencing [99], and in the relationship between self-silencing and psychological well-being. For example, there is evidence that whilst men report significantly higher self-silencing than women, they also report lower depression [96,100], a finding reported in a recent study of cancer carers [98], whereas self-silencing is positively correlated with depression in women [100]. The present study will examine the association between selfsilencing and sexual functioning, as part of a broader multifactorial analysis, in women and men with cancer, as well as partners of a person with cancer, the first study to do so.

Cancer affects not only the person who receives a cancer diagnosis, but also their significant other, leading to the description of cancer as a 'we-disease' [88]. Whilst the experiences of partners are often neglected in research on sexuality and intimacy post-cancer $[101,102]$, there is growing acknowledgement of their unmet needs in this area [82,103-105]. Reported disruptions for partners include decreases in sexual drive, fear of initiating sex with their partner, difficulty regaining a level of 'normality' within the sexual relationship, sexual communication difficulties, and feeling unwanted and unattractive because of the cessation of sex $[34,83,102,106-109]$. The present study will, therefore, examine the sexual experiences of partners in comparison with people with cancer, across sexual and non-sexual cancer types, to address this gap in the research literature.

\section{Study aims and research questions}

The aim of this study is to examine the nature of changes in sexual functioning post-cancer and to evaluate the interaction between sexual function and psychological distress, quality of life, and relationship satisfaction and communication. The following research questions are examined. For both men and women with cancer, and their partners, across sexual and non-sexual cancers: How important is sexuality post-cancer? What are the changes in sexual functioning reported before and post-cancer? What psycho-social factors are associated with reductions in sexual functioning post-cancer? What is the relative contribution of psycho-social factors in predicting reductions in sexual functioning?

\section{Method}

Participants

Six hundred and fifty seven people with cancer (535 women, 122 men) and 148 partners (87 women, 61 men) took part in the study, part of a larger mixed methods study examining the construction and experience of changes to sexuality after cancer. We recruited Australian participants nationally through cancer support groups, media stories in local press, advertisements in cancer and carer specific newsletters, hospital clinics, and local Cancer Council websites and telephone helplines. After reading detailed information describing the research team, the study, consent and complaint procedures, participants completed an online or postal questionnaire examining their experiences of sexuality and intimacy post-cancer. As detailed in the study information sheet, consent to participate was implied through the completion and return of the questionnaire. At the end of the survey, participants indicated whether they would like to be considered to take part in a one hour interview, to discuss changes to sexuality in more depth (additional written consent was obtained for the interviews, with qualitative data reported elsewhere) [110-114]. Two individuals, a person with cancer and a partner, nominated by a cancer consumer organization acted as consultants on the project, commenting on the design, method and interpretation of results. We received ethical approval from the University of Western Sydney Human Research Ethics Committee, and from three Health Authorities (Sydney West Area Health Service, South East Sydney Illawarra Health Service, and St Vincent's Hospital, Sydney), from which participants were drawn.

\section{Measures \\ Changes in Sexual Functioning Questionnaire (CSFQ-14)}

A 14 item validated instrument that provides a global measure of sexual functioning, using a 5 point Likert scale [115]. It has five subscales identifying different aspects of sexual functioning: desire/frequency; desire/ interest; arousal excitement; orgasm/completion; and pleasure, with higher scores indicating higher levels of reported functioning. In reliability testing, the Cronbach alpha coefficients for the total CSFQ-14 score of .90 for the female version and .89 for the male version have been found [115].

\section{Hospital Anxiety and Depression Scale (HADS)}

A 14 item validated measure developed to measure anxiety and depression in non-psychiatric populations [116]. Each subscale HADSA (anxiety) and HADSD (depression) has a maximum possible score of 21 , with a score of 
between 8 and above recommended for "caseness", the cut-off for clinical diagnosis. A score of 8-10 is categorized borderline, and a score of 11 and above categorized as abnormal in relation to caseness [117]. In a review of the psychometric literature on HADS, Cronbach alpha coefficients for HADS-A varied from .68 to .93 (mean .83) and for HADS-D from .67 to .90 (mean .82) [117].

\section{Medical outcomes study health survey short form (SF-12)}

Used to measure health-related quality of life. This measure has been used to evaluate functional states in depressed, chronically ill and healthy populations. The SF-12 is comprised of 12 items, measuring two components: mental health and physical health [118]. Participants rate the degree to which their quality of life is compromised due to their health, on a series of Likert scales. High scores indicate a better quality of life. The SF-12 has good internal consistency and test-retest reliability. Sufficient evidence for the internal consistency of the revised SF-12 as been found (Cronbach alpha coefficients of 0.72 to 0.89 ) [119].

\section{Brief Dyadic Adjustment Scale (DAS)}

A 7 item validated instrument which examines relationship satisfaction and cohesion, using a 6-point Likert scale [120]. Higher scores are indicative of higher levels of relationship satisfaction. DAS has shown good internal consistency with Cronbach alpha coefficient of .85 reported [121].

\section{Dyadic sexual communication scale}

A 13 item scale assessing perceptions of the communication process encompassing sexual relationships, using a 6-point Likert scale, with higher scores associated with better quality of perceived communication [122]. The internal consistency of the DSC has been tested among a cohabitating sample, with a Cronbach alpha coefficient of .83 found [122].

\section{The Silencing the Self Scale (STSS)}

A standardized questionnaire consisting of 31 items measuring the extent to which individuals endorse selfsilencing thoughts and actions in intimate relationships, using a 5 point Likert scale [92]. In addition to a Global score, the four subscales are: Care as Self-Sacrifice (e.g. Caring means putting the other person's needs in front of my own), Silencing the Self (e.g. I don't speak my feelings in an intimate relationship when I know they will cause disagreement), Externalized Self Perception (e.g. I tend to judge myself by how I think other people see me) and The Divided Self (e.g. Often I look happy enough on the outside, but inwardly I feel angry and rebellious). High scores indicate greater self-silencing. The internal consistency of total STSS and subscales has been found to range from Cronbach alpha coefficients of .65 to .94 [95].

\section{Ratings of sexual importance and activity}

Were obtained by participants responding to separate items on the importance of sex as a part of their relationship and as a part of their life on a three point scale: not important, somewhat important, very important. Participants also reported with a yes/no response whether their sexual activities had changed since the onset of cancer.

\section{Statistical analysis}

Univariate analyses were conducted to compare women and men on each of the socio-demographic variables of interest separately for people with cancer (PWC) and partners of people with cancer (PPWC). For continuous variables, one-way ANOVA were conducted with gender as the grouping variable, and the chi square test for independence used for frequency data. Participants reported a range of cancer types, which were categorized into sexual (breast, gynecological, prostate, genito-urinary) and non-sexual (hematological/blood, digestive/gastrointestinal, neurologic, skin and other) for the purpose of analysis. The chi square test for independence was used to test for group differences between sexual and non-sexual cancer types, and women and men, on measures of sexual importance and activity, for both PWC and PPWC. To assess change in sexual functioning after cancer, paired sample t-tests were conducted separately for women and men for PWC and PPWC. Preliminary analyses to multiple regression analyses included independent sample $\mathrm{t}$-tests to assess gender differences in mean scores for all potential predictor variables, and Pearson's correlations to assess associations between the sexual functioning measures and the criterion total sexual functioning and potential predictor variables for women and men across PWC and PPWC. Finally, to evaluate the relationship between the set of potential predictor variables and the criterion, and identify those variables responsible for the variation in the criterion, standard multiple linear regression analyses were conducted for women and men in the PWC and PPWC samples. Exact alpha levels are reported for all statistical tests, with table notations indicating significance at the $.05, .01$ or greater than .001 levels where relevant. Ninety-five precent confidence intervals $(\mathrm{CI})$ are reported for effect sizes involving principal outcomes.

\section{Results}

\section{Descriptive data}

Tables 1 and 2 present the sample demographics by gender for the PWC and PPWC samples. Years since first diagnosis of cancer, ethnicity profile, relationship status, and current involvement in a sexual relationship 
Table 1 Sample characteristics by gender for People with Cancer (PWC)

\begin{tabular}{|c|c|c|c|c|c|c|c|}
\hline \multirow[b]{2}{*}{ Variable } & \multicolumn{2}{|c|}{ Women } & \multicolumn{2}{|c|}{ Men } & \multirow{2}{*}{$\begin{array}{l}\text { Test for group difference } \\
F\end{array}$} & \multirow{2}{*}{$\begin{array}{c}\text { Significance } \\
p\end{array}$} & \multirow{2}{*}{$\begin{array}{c}\text { Effect size } \\
\qquad 2\end{array}$} \\
\hline & $n$ & $M(S D)$ & $n$ & $M(S D)$ & & & \\
\hline Patient age & 535 & $50.7(10.9)$ & 122 & $61.1(14.3)$ & 79.01 & $<0.001$ & 0.108 \\
\hline Years since first diagnosis & 533 & $4.9(5.3)$ & 122 & $5.3(5.4)$ & 0.53 & 0.468 & 0.001 \\
\hline \multirow[t]{2}{*}{ Length of current relationship } & 515 & $19.8(13.7)$ & 118 & $25.7(16.8)$ & 16.55 & $<0.001$ & 0.026 \\
\hline & $n$ & $\%$ & $n$ & $\%$ & $x^{2}$ & $p$ & $\varphi$ \\
\hline Ethnicity: & & & & & 0.51 & 0.774 & 0.028 \\
\hline Aust/White European & 508 & 95.7 & 114 & 94.2 & & & \\
\hline Asian & 14 & 2.6 & 4 & 3.3 & & & \\
\hline Other & 9 & 1.7 & 3 & 2.5 & & & \\
\hline Cancer type: & & & & & 519.19 & $<0.001$ & 0.364 \\
\hline Breast & 425 & 80 & - & - & & & \\
\hline Gynecologic & 45 & 8.5 & - & - & & & \\
\hline Prostate & - & - & 87 & 72.5 & & & \\
\hline Genitourinary (other) & 4 & 0.8 & 7 & 5.8 & & & \\
\hline Hematological/Blood & 23 & 4.3 & 14 & 11.7 & & & \\
\hline Digestive/Gastrointestinal & 11 & 2.1 & 4 & 3.3 & & & \\
\hline Neurologic & 6 & 1.1 & 4 & 3.3 & & & \\
\hline Skin & 8 & 1.5 & 2 & 1.7 & & & \\
\hline Other $^{\mathrm{a}}$ & 9 & 1.7 & 2 & 1.7 & & & \\
\hline Cancer classification: & & & & & 10.52 & .001 & 0.127 \\
\hline Sexual cancer type & 474 & 89.3 & 94 & 78.3 & & & \\
\hline Non-sexual cancer type & 57 & 10.7 & 26 & 21.7 & & & \\
\hline Stage of disease: & & & & & 27.19 & $<0.001$ & 0.188 \\
\hline No longer detectable/In remission & 430 & 80.8 & 71 & 58.7 & & & \\
\hline Receiving treatment & 16 & 3.0 & 7 & 5.8 & & & \\
\hline Other ${ }^{b}$ & 86 & 16.2 & 43 & 35.5 & & & \\
\hline Relationship status: & & & & & 3.12 & 0.374 & 0.032 \\
\hline Partnered - Living together & 414 & 77.4 & 96 & 78.7 & & & \\
\hline Partnered - Not living together & 34 & 6.4 & 10 & 8.2 & & & \\
\hline Not in a relationship & 76 & 14.2 & 16 & 13.1 & & & \\
\hline Other/Not specified & 11 & 2.1 & - & - & & & \\
\hline Sexual identity: & & & & & 405.16 & $<0.001$ & 0.858 \\
\hline Heterosexual & 434 & 96.7 & 92 & 91.1 & & & \\
\hline Non heterosexual & 15 & 3.3 & 9 & 8.9 & & & \\
\hline Current sexual relationship: & & & & & 0.99 & 0.319 & 0.039 \\
\hline Yes & 404 & 76.2 & 87 & 71.9 & & & \\
\hline No & 126 & 23.8 & 34 & 18.6 & & & \\
\hline
\end{tabular}

Note ${ }^{\text {a } O t h e r " ~ i n c l u d e s: ~ R e s p i r a t o r y / T h o r a c i c, ~ H e a d ~ \& ~ N e c k, ~ v a r i o u s, ~ e a c h ~ l e s s ~ t h a n ~} 1 \%$; ${ }^{\mathrm{b}}$ "Other" includes: a new different cancer; active monitoring; outcome not specified.

did not differ between female and male PWC. However, men were significantly older, 61.1 versus 50.7 years old, had been in their current relationship longer, 25.7 years versus 19.8 years, were more likely to identify as nonheterosexual, $8.9 \%$ versus $3.3 \%$, were less likely to report a sexual cancer, $78 \%$ versus $89 \%$, and were less likely to be in remission, $59 \%$ versus $81 \%$ (Table 1). For the PPWC sample, partner age, length of current relationship, relationship status, sexual identity, involvement in a current sexual relationship, ethnicity profile, years since partner's 
Table 2 Sample characteristics by gender for partners of People with Cancer (PPWC)

\begin{tabular}{|c|c|c|c|c|c|c|c|}
\hline \multirow[b]{2}{*}{ Variable } & \multicolumn{2}{|c|}{ Women } & \multicolumn{2}{|r|}{ Men } & \multirow{2}{*}{$\begin{array}{c}\text { Test for group difference } \\
\text { F }\end{array}$} & \multirow{2}{*}{$\begin{array}{c}\text { Significance } \\
p\end{array}$} & \multirow{2}{*}{$\begin{array}{l}\text { Effect size } \\
\qquad \eta 2\end{array}$} \\
\hline & $n$ & $M(S D)$ & $n$ & $M(S D)$ & & & \\
\hline Partner age & 87 & $54.1(13.5)$ & 61 & $54.8(11.1)$ & 0.11 & 0.738 & 0.001 \\
\hline Years since partner's first diagnosis & 87 & $2.9(2.0)$ & 61 & $2.9(2.0)$ & 0.01 & 0.932 & 0.000 \\
\hline \multirow[t]{2}{*}{ Length of current relationship } & 87 & $25.0(16.2)$ & 61 & $23.8(13.2)$ & 0.24 & 0.629 & 0.002 \\
\hline & $n$ & $\%$ & $n$ & $\%$ & $x^{2}$ & $p$ & $\varphi$ \\
\hline Ethnicity: & & & & & 0.85 & 0.653 & 0.056 \\
\hline Aust/White European & 82 & 97.6 & 57 & 95.0 & & & \\
\hline Asian & 1 & 1.2 & 2 & 3.3 & & & \\
\hline Other & 1 & 1.2 & 1 & 1.7 & & & \\
\hline Cancer type: & & & & & 60.10 & $<0.001$ & 0.297 \\
\hline Breast & 4 & 4.6 & 29 & 48.3 & & & \\
\hline Gynecologic & 4 & 4.6 & 9 & 15 & & & \\
\hline Prostate & 35 & 40.2 & 2 & 3.3 & & & \\
\hline Genitourinary (other) & 6 & 6.9 & - & - & & & \\
\hline Hematological/Blood & 15 & 17.2 & 10 & 16.7 & & & \\
\hline Digestive/Gastrointestinal & 11 & 12.6 & 6 & 10.0 & & & \\
\hline Neurologic & 2 & 2.3 & 1 & 1.7 & & & \\
\hline Skin & 2 & 2.3 & 1 & 1.7 & & & \\
\hline Other ${ }^{a}$ & 8 & 9.2 & 2 & 3.3 & & & \\
\hline Cancer classification: & & & & & 1.60 & 0.207 & 0.104 \\
\hline Sexual cancer type & 49 & 56.3 & 40 & 66.7 & & & \\
\hline Non-sexual cancer type & 38 & 43.7 & 20 & 33.3 & & & \\
\hline Stage of disease: & & & & & 3.11 & 0.375 & 0.095 \\
\hline No longer detectable/In remission & 52 & 59.8 & 41 & 67.2 & & & \\
\hline Receiving treatment & 2 & 2.3 & 3 & 4.9 & & & \\
\hline Other $^{\mathrm{b}}$ & 33 & 37.9 & 17 & 27.9 & & & \\
\hline Relationship status: & & & & & 0.12 & 0.896 & 0.011 \\
\hline Partnered - Living together & 79 & 90.8 & 55 & 90.2 & & & \\
\hline Partnered - Not living together & 8 & 9.2 & 6 & 9.8 & & & \\
\hline Sexual orientation: & & & & & 36.16 & 0.525 & 0.086 \\
\hline Heterosexual & 79 & 90.8 & 55 & 90.2 & & & \\
\hline Non heterosexual & 8 & 9.2 & 6 & 9.8 & & & \\
\hline Current sexual relationship: & & & & & 0.12 & 0.729 & 0.039 \\
\hline Yes & 70 & 81.4 & 51 & 83.6 & & & \\
\hline No & 16 & 18.6 & 10 & 16.4 & & & \\
\hline
\end{tabular}

Note a "Other" includes: Respiratory/Thoracic, Head \& Neck, various, each less than 1.5\%; "Other" includes: a new different cancer; active monitoring; outcome not specified.

first diagnosis of cancer, sexual or non-sexual cancer classification, and stage of disease, did not differ by gender (Table 2).

Measures of sexual importance and sexual activity for PWC and PPWC according to gender and sexual or non-sexual cancer classification are presented in Tables 3 and 4. PWC men were more likely to rate the importance of sex to their relationships and as a part of life as very or somewhat important $(97.9 \%$ and $96.6 \%$, respectively) than women (86.2\% and $78.2 \%$, respectively). There was no significant difference in the reporting of changes in sexual activities since the onset of caner for men (84.6\%) and women (76.8\%), with the majority of both groups reporting a change. For PPWC, men (91.8\%) were more likely than women $(84.7 \%)$ to rate sex as very to somewhat important as a part of life. 
Table 3 Sexual importance and activity by gender and cancer classification for People with Cancer (PWC)

\begin{tabular}{|c|c|c|c|c|c|c|c|c|c|c|c|c|c|c|}
\hline \multirow[b]{2}{*}{ Item/Variable } & \multicolumn{2}{|c|}{ Women } & \multicolumn{2}{|c|}{ Men } & \multicolumn{3}{|c|}{ Test for group difference } & \multicolumn{2}{|c|}{$\begin{array}{l}\text { Sexual } \\
\text { cancer }\end{array}$} & \multicolumn{2}{|c|}{$\begin{array}{l}\text { Non-sexual } \\
\text { cancer }\end{array}$} & \multicolumn{3}{|c|}{ Test for group difference } \\
\hline & $n$ & $\%$ & $n$ & $\%$ & $x^{2}$ & $p$ & $\varphi$ & $n$ & $\%$ & $N$ & $\%$ & $x^{2}$ & $p$ & $\varphi$ \\
\hline Sex important part of the relationship: & & & & & 13.17 & 0.001 & 0.158 & & & & & 2.715 & 0.257 & 0.072 \\
\hline Very important & 148 & 34.3 & 45 & 48.4 & & & & 162 & 35.7 & 30 & 46.2 & & & \\
\hline Somewhat important & 224 & 51.9 & 46 & 49.5 & & & & 238 & 52.4 & 28 & 43.1 & & & \\
\hline Not important & 60 & 13.9 & 2 & 2.2 & & & & 54 & 11.9 & 7 & 10.8 & & & \\
\hline Sex important part of life: & & & & & 39.59 & $<0.001$ & 0.248 & & & & & 9.965 & 0.007 & 0.125 \\
\hline Very important & 125 & 23.7 & 57 & 48.7 & & & & 146 & 26.2 & 35 & 42.7 & & & \\
\hline Somewhat important & 288 & 54.5 & 56 & 47.9 & & & & 304 & 54.6 & 37 & 45.1 & & & \\
\hline Not important & 115 & 21.8 & 4 & 3.4 & & & & 107 & 19.2 & 10 & 12.2 & & & \\
\hline $\begin{array}{l}\text { Change in sexual activities since } \\
\text { onset of cancer: }\end{array}$ & & & & & 3.417 & 0.065 & 0.074 & & & & & 2.951 & 0.086 & 0.069 \\
\hline Yes & 394 & 76.8 & 99 & 84.6 & & & & 432 & 79.1 & 55 & 70.5 & & & \\
\hline No & 119 & 23.2 & 18 & 15.4 & & & & 114 & 20.9 & 23 & 29.5 & & & \\
\hline
\end{tabular}

The rankings of the importance of sex to the relationship, and the report of changes to sexual activity postcancer did not differ between the sexual and non-sexual cancer classifications, with the majority in both groups nominating importance and a change in activities. Nonsexual cancer PWC were more likely to rate the importance of sex as a part of life as very or somewhat important than sexual cancer PWC (87.8\% and $80.8 \%$ respectively). For the PPWC sample, cancer classification groupings did not differ in reports on sexual importance and activity levels, with the majority in both groups indicating the importance of sex to the relationship and life, and a change in activities, post-cancer. As the impact of cancer upon sexual importance and activity is sufficiently similar across sexual/non-sexual cancer classification groups for the PWC and PPWC samples, subsequent analyses did not test for differences between these groups.

\section{Sexual functioning according to gender}

Paired sample t-tests were conducted for both women and men PWC and PPWC on CSFQ subscales and total scores (Tables 5 and 6) comparing changes in sexual functioning before cancer to after cancer. Cross gender statistical comparison on the CSFQ is not possible, as the scales are specific to men and women. For all CSFQ scores across women and men PWC, sexual functioning scores were significantly lower after cancer than before cancer. Cohen's effect size values ranged from $d=1.228$ for the change in women's sexual desire/interest scores

Table 4 Sexual importance and activity by gender and cancer classification for partners of People with Cancer (PPWC)

\begin{tabular}{|c|c|c|c|c|c|c|c|c|c|c|c|c|c|c|}
\hline \multirow[b]{2}{*}{ Item/Variable } & \multicolumn{2}{|c|}{ Women } & \multicolumn{2}{|c|}{ Men } & \multicolumn{3}{|c|}{ Test for group difference } & \multicolumn{2}{|c|}{$\begin{array}{l}\text { Sexual } \\
\text { cancer }\end{array}$} & \multicolumn{2}{|c|}{$\begin{array}{l}\text { Non-sexual } \\
\text { cancer }\end{array}$} & \multicolumn{3}{|c|}{ Test for group difference } \\
\hline & $n$ & $\%$ & $n$ & $\%$ & $x^{2}$ & $p$ & $\varphi$ & $\bar{n}$ & $\%$ & $\bar{n}$ & $\%$ & $x^{2}$ & $p$ & $\varphi$ \\
\hline Sex important part of the relationship: & & & & & 5.24 & 0.073 & 0.202 & & & & & 0.80 & 0.672 & 0.079 \\
\hline Very important & 24 & 31.6 & 27 & 50.9 & & & & 33 & 42.9 & 18 & 35.3 & & & \\
\hline Somewhat important & 41 & 53.9 & 22 & 41.5 & & & & 35 & 45.5 & 27 & 43.5 & & & \\
\hline Not important & 11 & 14.5 & 4 & 7.5 & & & & 9 & 11.7 & 6 & 11.8 & & & \\
\hline Sex important part of life: & & & & & 9.43 & 0.009 & 0.254 & & & & & 2.11 & 0.348 & 0.121 \\
\hline Very important & 20 & 23.5 & 29 & 47.5 & & & & 31 & 35.6 & 18 & 31.0 & & & \\
\hline Somewhat important & 52 & 61.2 & 27 & 44.3 & & & & 43 & 49.4 & 35 & 60.3 & & & \\
\hline Not important & 13 & 15.3 & 5 & 8.2 & & & & 13 & 14.9 & 5 & 8.7 & & & \\
\hline $\begin{array}{l}\text { Change in sexual activities since } \\
\text { onset of cancer: }\end{array}$ & & & & & 1.37 & 0.163 & 0.098 & & & & & 0.68 & 0.411 & 0.035 \\
\hline Yes & 62 & 75.6 & 40 & 66.7 & & & & 64 & 73.6 & 38 & 70.4 & & & \\
\hline No & 20 & 24.4 & 20 & 33.3 & & & & 23 & 26.4 & 16 & 29.6 & & & \\
\hline
\end{tabular}

Note. The CSFQ Sexual Pleasure Subscale is only available for 'after cancer'. 
Table 5 CSFQ subscales by gender for People with Cancer (PWC)

\begin{tabular}{|c|c|c|c|c|c|c|c|c|c|c|}
\hline Subscale & Women & $M(S D)$ & $\begin{array}{c}\text { Test for group } \\
\text { difference } \\
t\end{array}$ & $p$ & d & Men & $M(S D)$ & $\begin{array}{c}\text { Test for group } \\
\text { difference } \\
t\end{array}$ & $p$ & $\begin{array}{c}\text { Effect size } \\
d\end{array}$ \\
\hline Sexual desire/frequency & & & 21.28 & $<0.001$ & 1.403 & & & 8.73 & $<0.001$ & 1.388 \\
\hline Before cancer & 520 & $6.85(1.64)$ & & & & 117 & $7.40(1.33)$ & & & \\
\hline After cancer & 520 & $4.92(1.86)$ & & & & 117 & $5.86(1.97)$ & & & \\
\hline Sexual desire/interest & & & 16.63 & $<0.001$ & 1.228 & & & 6.75 & $<0.001$ & 1.285 \\
\hline Before cancer & 516 & $8.82(2.51)$ & & & & 115 & $10.74(2.12)$ & & & \\
\hline After cancer & 516 & $6.77(2.62)$ & & & & 115 & $9.17(2.44)$ & & & \\
\hline Sexual arousal & & & 21.01 & $<0.001$ & 1.459 & & & 16.96 & $<0.001$ & 1.807 \\
\hline Before cancer & 509 & $11.17(3.01)$ & & & & 114 & $13.69(1.42)$ & & & \\
\hline After cancer & 509 & $7.27(3.12)$ & & & & 114 & $9.26(2.52)$ & & & \\
\hline Sexual orgasm & & & 18.13 & $<0.001$ & 1.342 & & & 16.32 & $<0.001$ & 1.924 \\
\hline Before cancer & 504 & $12.04(2.95)$ & & & & 109 & $12.29(1.90)$ & & & \\
\hline After cancer & 504 & $8.72(3.97)$ & & & & 109 & $6.88(3.32)$ & & & \\
\hline Total sexual functioning & & & 13.67 & $<0.001$ & 1.359 & & & 10.49 & $<0.001$ & 1.547 \\
\hline Before cancer & 446 & $42.22(7.37)$ & & & & 104 & $46.55(5.36)$ & & & \\
\hline After cancer & 446 & $34.73(10.45)$ & & & & 104 & $36.48(9.30)$ & & & \\
\hline
\end{tabular}

through to $d=1.924$ for the change in men's sexual orgasm scores, suggesting a high practical significance in the level of pre to post cancer change.

For the PPWC sample, all CSFQ sexual functioning scores for women were significantly lower after cancer as compared to before cancer scores. For men, all postcancer sexual functioning scores were lower than before cancer scores with the exceptions of sexual desire/ interest and total sexual functioning scores, where differences did not reach statistical significance. In all instances where statistical significance was reached, Cohen's effect size values indicated a moderate to high practical significance in the observed change from pre to post cancer levels.

Table 6 CSFQ subscales by gender for partners of People with Cancer (PPWC)

\begin{tabular}{|c|c|c|c|c|c|c|c|c|c|c|}
\hline Subscale & Women & $M(S D)$ & $\begin{array}{c}\text { Test for group } \\
\text { difference } \\
t\end{array}$ & $\begin{array}{l}\text { Sign. } \\
\quad p\end{array}$ & d & $n$ & $M(S D)$ & $\begin{array}{c}\text { Test for group } \\
\text { difference } \\
t\end{array}$ & $\begin{array}{l}\text { Sign. } \\
p\end{array}$ & $\begin{array}{c}\text { Effect size } \\
\qquad\end{array}$ \\
\hline Sexual desire/frequency & & & 9.75 & $<0.001$ & 1.125 & & & 6.38 & $<0.001$ & 1.327 \\
\hline Before cancer & 80 & $6.96(1.44)$ & & & & 58 & $7.28(1.47)$ & & & \\
\hline After cancer & 80 & $5.24(1.62)$ & & & & 58 & $5.98(1.57)$ & & & \\
\hline Sexual desire/interest & & & 3.93 & $<0.001$ & 1.031 & & & 1.45 & 0.152 & 0.711 \\
\hline Before cancer & 77 & $8.26(2.58)$ & & & & 55 & 11.13(5.94) & & & \\
\hline After cancer & 77 & $7.38(2.49)$ & & & & 55 & $10.04(2.46)$ & & & \\
\hline Sexual arousal & & & 4.62 & $<0.001$ & 0.939 & & & 3.85 & $<0.001$ & 1.192 \\
\hline Before cancer & 79 & $11.51(5.18)$ & & & & 56 & $8.39(1.63)$ & & & \\
\hline After cancer & 79 & $9.03(3.05)$ & & & & 56 & $7.82(1.82)$ & & & \\
\hline Sexual orgasm & & & 3.73 & $<0.001$ & 0.946 & & & 2.54 & 0.014 & 1.029 \\
\hline Before cancer & 77 & $12.45(5.45)$ & & & & 52 & $17.54(6.10)$ & & & \\
\hline After cancer & 77 & $9.60(5.21)$ & & & & 52 & $15.48(2.69)$ & & & \\
\hline Total sexual functioning & & & 3.39 & 0.001 & 1.244 & & & 1.057 & .296 & 1.046 \\
\hline Before cancer & 70 & $41.01(7.28)$ & & & & 50 & $46.74(13.21)$ & & & \\
\hline After cancer & 70 & $37.13(9.61)$ & & & & 50 & $44.78(7.14)$ & & & \\
\hline
\end{tabular}

Note. The CSFQ Sexual Pleasure Subscale is only available for 'after cancer'. 


\section{Health related QoL, psychological distress and relationship measures according to gender}

Univariate analyses were used to compare women and men on health related QoL, psychological distress and relationship variables of interest. With assumptions of normality and homogeneity of variance met in all instances, independent $\mathrm{t}$-tests were conducted with gender as the grouping variable. Table 7 presents the descriptive data and comparisons between gender for all variables for the PWC sample. For mental health related quality of life, anxiety, dyadic adjustment and sexual communication, and three STSS subscales, results indicated a statistically significant difference for women and men, with women experiencing higher levels of anxiety and 'externalized self perception' self-silencing, and lower levels of mental health related QOL, relationship satisfaction and sexual communication. For the STSS subscales 'silencing the self' and 'care as self-sacrifice', men reported significantly higher self-silencing scores than women. For the PPWC sample, results indicated that women reported a higher 'externalized self-perception' STSS subscale score than men, with the differences between women and men on all other variables not being statistically significant (Table 8 ).

The correlations between all potential predictor variables and sexual functioning measures according to gender are presented in Table 9 for the PWC sample. For women, all health related QoL, psychological distress and relationship measures were significantly associated with total sexual functioning scores and the majority of sexual functioning subscale scores on the CSFQ. Significant positive correlations were observed for the SF12 subscales, DAS and DSCS and sexual functioning scores, whereas HADS and STSS subscales were significantly inversely correlated with sexual functioning scores. For men in the PWC sample, SF12 health related QoL and DAS measures had significant positive correlations with sexual functioning total scores, as compared to the 'silencing the self' and 'care as self-sacrifice' STSS subscales which were negatively associated with total sexual functioning.

For the PPWC sample, fewer potential predictor variables were significantly correlated with sexual functioning scores (Table 10). For women, the relationship between relationship satisfaction and sexual communication measures - DAS and DSCS - were significantly positively correlated with sexual functioning total and the majority of the subscales, whilst the 'care as self-sacrifice' subscale of the STSS was negatively associated with sexual functioning. Significant positive correlations were observed between the physical health summary score of the SF12 and relationship communication (DSCS) and sexual functioning total and subscales scores, with the STSS 'silencing the self' subscale inversely related to sexual functioning for men PPWC.

\section{Prediction of sexual functioning}

Standard multiple linear regression analyses were conducted to evaluate how well health related QoL, psychological distress, relationship satisfaction, sexual communication and self-silencing measures predicted women and men's total sexual functioning scores for the PWC and PPWC samples. Evaluations of assumptions were satisfactory with no outliners with a standardized residual $>3$, and no cases found with a Mahalanobis distance score of $p<.001$ for all analyses performed. To maximize the cases-to-IVs-ratio, potential predictors with non-significant zero-order correlations (as identified in Tables 9 and 10) were excluded in the regression analyses [123]. In all analyses, no multicollinearity

Table 7 Means (standard deviations) and comparisons between gender for all potential predictor variables for People with Cancer (PWC)

\begin{tabular}{|c|c|c|c|c|c|c|}
\hline Variable & $\begin{array}{c}\text { Women } \\
M(S D)\end{array}$ & $\begin{array}{c}\text { Men } \\
M(S D)\end{array}$ & $t(655)$ & $p$ & $95 \% \mathrm{Cl}$ & $\eta 2$ \\
\hline SF12-Physical component summary & $46.33(10.88)$ & $46.88(10.23)$ & -0.51 & .609 & {$[-2.67,1.57]$} & .000 \\
\hline SF12-Mental component summary & $45.25(11.42)$ & $48.37(10.42)$ & -2.77 & .006 & {$[-5.34,-0.91]$} & .012 \\
\hline HADS-Anxiety & $9.75(2.41)$ & $8.68(3.12)$ & 4.19 & $<.001$ & {$[0.57,1.58]$} & .026 \\
\hline HADS-Depression & $8.12(2.15)$ & $7.78(3.05)$ & 1.65 & .099 & {$[-0.73,0.85]$} & .004 \\
\hline Dyadic Adjustment Scale (DAS) & $27.73(4.09)$ & $28.57(3.83)$ & -1.99 & .047 & {$[-1.65,-0.01]$} & .006 \\
\hline Dyadic Sexual Communication (DSCS) & $46.06(11.63)$ & $48.47(11.04)$ & -2.03 & .043 & {$[-4.74,-0.73]$} & .007 \\
\hline \multicolumn{7}{|l|}{ Silencing the Self Scale (STSS) } \\
\hline Externalized self perception & $17.34(5.48)$ & $15.69(5.21)$ & 3.01 & .003 & {$[0.57,2.73]$} & 0.14 \\
\hline Silencing the self & $23.55(7.74)$ & $26.78(6.77)$ & -4.16 & $<.001$ & {$[-4.76,1.71]$} & .027 \\
\hline Care as self sacrifice & $24.78(5.93)$ & $31.49(5.58)$ & -11.16 & $<.001$ & {$[-7.89,-5.53]$} & .165 \\
\hline Divided self & $16.38(6.45)$ & $16.58(6.45)$ & -0.30 & .767 & {$[-1.51,1.11]$} & .000 \\
\hline
\end{tabular}


Table 8 Means (standard deviations) and comparisons between gender for all potential predictor variables for Partners of People with Cancer (PPWC)

\begin{tabular}{|c|c|c|c|c|c|c|}
\hline & Women & Men & & & & \\
\hline Variable & $M(S D)$ & $M(S D)$ & $t(655)$ & $p$ & $95 \% \mathrm{Cl}$ & $\eta 2$ \\
\hline SF12-Physical component summary & $51.05(9.12)$ & $51.28(8.24)$ & -0.16 & .873 & {$[-3.13,2.66]$} & .000 \\
\hline SF12-Mental component summary & $45.55(12.01)$ & $48.32(12.01)$ & -1.38 & .169 & {$[-6.74,-1.19]$} & .013 \\
\hline HADS-Anxiety & $11.10(2.49)$ & $11.59(2.93)$ & -1.10 & .275 & {$[-1.39,0.40]$} & .008 \\
\hline HADS-Depression & $8.80(2.02)$ & $8.78(2.35)$ & 0.06 & .956 & {$[-0.73,0.74]$} & .000 \\
\hline Dyadic Adjustment Scale (DAS) & $28.33(3.91)$ & $29.29(3.46)$ & -1.52 & .130 & {$[-2.21,0.29]$} & .016 \\
\hline Dyadic Sexual Communication (DSCS) & $46.43(13.04)$ & $48.65(10.20)$ & -1.10 & .275 & {$[-6.22,1.78]$} & .008 \\
\hline \multicolumn{7}{|l|}{ Silencing the Self Scale (STSS) } \\
\hline Externalized self perception & $17.76(8.90)$ & $14.97(5.78)$ & 2.13 & .035 & {$[0.20,5.39]$} & .031 \\
\hline Silencing the self & $26.05(8.13)$ & $25.93(9.54)$ & 0.83 & .934 & {$[-2.79,3.03]$} & .000 \\
\hline Care as self sacrifice & $28.71(8.39)$ & $30.15(6.10)$ & -1.12 & .267 & {$[-3.99,1.11]$} & .009 \\
\hline Divided self & $15.70(6.49)$ & $15.31(6.61)$ & 0.35 & .724 & {$[-1.80,2.59]$} & .001 \\
\hline
\end{tabular}

Table 9 Correlations among CSFQ subscales scores and potential predictor variables by gender for People with Cancer (PWC)

\begin{tabular}{|c|c|c|c|c|c|c|}
\hline \multirow[b]{2}{*}{ Variable } & \multirow[b]{2}{*}{$\begin{array}{l}\text { Sexual desire/ } \\
\text { frequency }\end{array}$} & \multicolumn{5}{|c|}{ Women } \\
\hline & & $\begin{array}{l}\text { Sexual desire/ } \\
\text { interest }\end{array}$ & $\begin{array}{l}\text { Sexual } \\
\text { arousal }\end{array}$ & $\begin{array}{l}\text { Sexual } \\
\text { orgasm }\end{array}$ & $\begin{array}{c}\text { Sexual } \\
\text { pleasure }\end{array}$ & $\begin{array}{l}\text { Total sexual } \\
\text { functioning }\end{array}$ \\
\hline SF12-Physical component summary & $.14^{* *}$ & $.15^{* *}$ & $.13^{* *}$ & $.14^{* *}$ & $.17^{* *}$ & $.15^{* *}$ \\
\hline SF12-Mental component summary & $20^{* *}$ & .07 & $.21^{* *}$ & $.21^{* *}$ & $.31^{* *}$ & $.22^{* *}$ \\
\hline HADS-Anxiety & $-.11^{*}$ & -.02 & $-.12^{* *}$ & $-.10^{*}$ & $-.18^{* *}$ & $-.16^{* *}$ \\
\hline HADS-Depression & $-.10^{*}$ & -.05 & $-.14^{* *}$ & $-.13^{* *}$ & $-.18^{* *}$ & $-.20^{* *}$ \\
\hline Dyadic Adjustment Scale (DAS) & $.28^{* *}$ & .04 & $.21^{* *}$ & $.13^{* *}$ & $.37^{* *}$ & $.22^{* *}$ \\
\hline Dyadic Sexual Communication (DSCS) & $.35^{* *}$ & $.18^{* *}$ & $.31^{* *}$ & $.31^{* *}$ & $.46^{* *}$ & $.34^{* *}$ \\
\hline \multicolumn{7}{|l|}{ Silencing the Self Scale (STSS) } \\
\hline Externalized self perception & $-.20^{* *}$ & $-.23^{* *}$ & $-.26^{* *}$ & $-.21^{* *}$ & $-.27^{* *}$ & $-.20^{* *}$ \\
\hline Silencing the self & $-.24^{* *}$ & $-.17^{* *}$ & $-.15^{* *}$ & $-.26^{* *}$ & $-.25^{* *}$ & $-.28^{* *}$ \\
\hline Care as self sacrifice & $-.10^{*}$ & $-.18^{* *}$ & $-.21^{* *}$ & $-.21^{* *}$ & -.08 & $-.18^{* *}$ \\
\hline \multirow[t]{2}{*}{ Divided self } & $-.34^{* *}$ & $-15^{* *}$ & $-.25^{* *}$ & $-.28^{* *}$ & $-.40^{* *}$ & $-3.32^{* *}$ \\
\hline & \multicolumn{6}{|c|}{ Men } \\
\hline SF12-Physical component summary & $.42^{* *}$ & .16 & .16 & $.23^{*}$ & $.36^{* *}$ & $.33^{* *}$ \\
\hline SF12-Mental component summary & $.16^{*}$ & .11 & .10 & .10 & $.16^{*}$ & $.17^{*}$ \\
\hline HADS-Anxiety & .04 & .02 & $-23^{* *}$ & $-20^{*}$ & -.04 & -.11 \\
\hline HADS-Depression & .02 & .03 & $-.19 *$ & $-.20^{*}$ & -.06 & -.09 \\
\hline Dyadic Adjustment Scale (DAS) & $.21^{*}$ & .09 & .07 & .12 & $.30^{* *}$ & $.19^{*}$ \\
\hline Dyadic Sexual Communication (DSCS) & $.17^{*}$ & -.10 & .06 & .13 & $.43^{* *}$ & .11 \\
\hline \multicolumn{7}{|l|}{ Silencing the Self Scale (STSS) } \\
\hline Externalized self perception & -.08 & $-.19^{*}$ & -.03 & -.06 & -.07 & -.15 \\
\hline Silencing the self & $-.25^{* *}$ & -.01 & $-.21^{*}$ & $-.24^{* *}$ & $-.25^{* *}$ & $-.24^{* *}$ \\
\hline Care as self sacrifice & $-.28^{* *}$ & -.04 & $-.27^{* *}$ & $-.25^{* *}$ & -.13 & $-.27^{* *}$ \\
\hline Divided self & -.12 & -.03 & -.09 & -.10 & $-.29^{* *}$ & -.12 \\
\hline
\end{tabular}

Note. ${ }^{*} p<.05 ;{ }^{* *} p<.01$, one-tailed. 
Table 10 Correlations among CSFQ subscales scores and potential predictor variables by gender for Partners of People with Cancer (PPWC)

\begin{tabular}{|c|c|c|c|c|c|c|}
\hline \multirow[b]{2}{*}{ Variable } & \multirow[b]{2}{*}{$\begin{array}{c}\text { Sexual desire/ } \\
\text { frequency }\end{array}$} & \multicolumn{5}{|c|}{ Women } \\
\hline & & $\begin{array}{c}\text { Sexual desire/ } \\
\text { interest }\end{array}$ & $\begin{array}{c}\text { Sexual } \\
\text { arousal }\end{array}$ & $\begin{array}{l}\text { Sexual } \\
\text { orgasm }\end{array}$ & $\begin{array}{c}\text { Sexual } \\
\text { pleasure }\end{array}$ & $\begin{array}{l}\text { Total sexual } \\
\text { functioning }\end{array}$ \\
\hline SF12-Physical component summary & $.22^{*}$ & $.24^{*}$ & $.28^{* *}$ & -.14 & .15 & .12 \\
\hline SF12-Mental component summary & .13 & .01 & .13 & .07 & $.32^{* *}$ & .13 \\
\hline HADS-Anxiety & .14 & .17 & .15 & .01 & $.20^{*}$ & .13 \\
\hline HADS-Depression & -.07 & -.03 & -.08 & -.18 & -.15 & -.18 \\
\hline Dyadic Adjustment Scale (DAS) & $.39^{* *}$ & .17 & $.24^{*}$ & .11 & $.51^{* *}$ & $.26^{* *}$ \\
\hline Dyadic Sexual Communication (DSCS) & $.49^{* *}$ & $.30^{* *}$ & $.37^{* *}$ & .04 & $.53^{* *}$ & $.33^{* *}$ \\
\hline \multicolumn{7}{|l|}{ Silencing the Self Scale (STSS) } \\
\hline Externalized self perception & $-.19^{*}$ & -.14 & .08 & -.11 & $-.23^{*}$ & -.13 \\
\hline Silencing the self & -.17 & -.10 & -.18 & -.09 & $-.22^{*}$ & -.16 \\
\hline Care as self sacrifice & .02 & .07 & -.15 & $-.26^{* *}$ & .00 & $-.19^{*}$ \\
\hline \multirow[t]{2}{*}{ Divided self } & $-.23^{*}$ & -.08 & -.14 & -.01 & $-.42^{* *}$ & -.17 \\
\hline & & & Men & & & \\
\hline SF12-Physical component summary & .06 & $.26^{*}$ & $.27^{*}$ & $.37^{* *}$ & .12 & $.33^{* *}$ \\
\hline SF12-Mental component summary & $.40^{* *}$ & $-.28^{*}$ & -.14 & -.04 & $.45^{* *}$ & .06 \\
\hline HADS-Anxiety & $.29^{*}$ & -.13 & -.15 & -.03 & $.33^{* *}$ & -.03 \\
\hline HADS-Depression & -.04 & .17 & .05 & -.02 & -.09 & .12 \\
\hline Dyadic Adjustment Scale (DAS) & .11 & -.10 & .01 & .11 & $.31^{* *}$ & .11 \\
\hline Dyadic Sexual Communication (DSCS) & $.49^{* *}$ & -.08 & .18 & .18 & $.64^{* *}$ & $.34^{* *}$ \\
\hline \multicolumn{7}{|l|}{ Silencing the Self Scale (STSS) } \\
\hline Externalized self perception & $-.22^{*}$ & $.40^{* *}$ & .12 & -.04 & $-.26^{*}$ & .07 \\
\hline Silencing the self & $-.25^{*}$ & -.09 & -.09 & $-.26^{*}$ & $-.25^{*}$ & $-.23^{*}$ \\
\hline Care as self sacrifice & -.14 & -.21 & .00 & -.11 & -.06 & -.08 \\
\hline Divided self & $-.31^{* *}$ & $.30^{*}$ & -.06 & -.20 & $-.48^{* *}$ & -.13 \\
\hline
\end{tabular}

Note. ${ }^{*} p<.05 ;{ }^{* *} p<.01$, one-tailed.

amongst predictors was detected with all correlation coefficients $<.90$. Tables 11 and 12 display the unstandardized regression coefficients $(B)$ and intercept, the standardized regression coefficients $(\beta)$, the semipartial correlations $\left(s r^{2}\right), R^{2}$, adjusted $R^{2}, R$, and the confidence limits for significant semipartial coefficients for the conducted regression analyses. Semipartial correlation coefficients are a useful measure for interpretation as they indicate how much each variable uniquely contributes to $R^{2}$ (total amount of variance in the criterion accounted for by the predictor variables) over and above that which can be accounted for by the other predictor variables.

For the women PWC sample, the full regression model significantly explained $22 \%$ the variance in total sexual functioning scores, $F(10,377)=9.85, p<.001$, adj $R^{2}=.22$, $95 \%$ CI $[-2.38,26.82]$. The relative strength of the individual predictors is presented in Table 11. Squared semipartial correlations indicate that four variables contributed uniquely to the prediction of sexual functioning scores, explaining $9 \%$ of the variance. The size and direction of the relationships indicated by the observed standardized regression coefficients suggests higher levels of sexual functioning for women PWC is associated with higher physical and mental health related quality of life and dyadic sexual communication, and lower depression. For the men PWC sample, the linear combination of five predictors significantly explained $12 \%$ of the variance in total sexual functioning scores, $F(5,95)=3.68, p=.004$, adj $R^{2}=.12,95 \%$ CI $[8.95,51.01]$. Only two predictors displayed significant semipartial correlations, suggesting that higher levels of sexual functioning in men PWC is uniquely associated with higher physical health related quality of life and lower levels of the 'care as self-sacrifice' subscale of the STSS.

Table 12 displays the results of the standard multiple regressions for the women and men PPWC samples. The full three variable regression model significantly explained $9 \%$ of the variance in total sexual functioning scores, $F(3,73)=3.50, p=.02$, adj $R^{2}=.09,95 \%$ CI 10.54 , 45.46], in the women PPWC sample. Only the semipartial 
Table 11 Multiple regression analysis predicting csfq total sexual functioning scores from predictor variables by gender for People with Cancer (PWC)

\begin{tabular}{|c|c|c|c|}
\hline \multirow[b]{2}{*}{ Variable } & \multicolumn{3}{|c|}{ Women } \\
\hline & B & $\beta$ & $s r^{2}$ (unique) \\
\hline SF12-Physical component summary & $.16^{* * *}$ & .17 & .03 \\
\hline SF12-Mental component summary & $.11^{*}$ & .12 & .01 \\
\hline HADS-Anxiety & .26 & .06 & \\
\hline HADS-Depression & $-.59^{*}$ & -.12 & .01 \\
\hline Dyadic Adjustment Scale (DAS) & .23 & .09 & \\
\hline Dyadic Sexual Communication (DSCS) & $.23^{* * *}$ & .25 & .04 \\
\hline \multicolumn{4}{|l|}{ Silencing the Self Scale (STSS) } \\
\hline Externalized self perception & .01 & .00 & \\
\hline Silencing the self & -.13 & -.09 & \\
\hline Care as self sacrifice & -.11 & -.06 & \\
\hline Divided self & .01 & .01 & \\
\hline (Intercept) & 12.20 & & \\
\hline$R^{2}$ & $.21^{\mathrm{a}}$ & & \\
\hline Total Adj. $R^{2}$ & .22 & & \\
\hline$R$ & $.46^{* * *}$ & & \\
\hline \multicolumn{4}{|l|}{$95 \%$ Confidence limits from 0.14 to 0.28} \\
\hline & & Men & \\
\hline SF12-Physical component summary & $.24^{*}$ & .24 & .05 \\
\hline SF12-Mental component summary & .09 & .09 & \\
\hline Dyadic Adjustment Scale (DAS) & .20 & .08 & \\
\hline \multicolumn{4}{|l|}{ Silencing the Self Scale (STSS) } \\
\hline Silencing the self & -.04 & -.03 & \\
\hline Care as self sacrifice & $-.42^{*}$ & -.24 & .05 \\
\hline (Intercept) & 29.98 & & \\
\hline$R^{2}$ & $.10^{\mathrm{b}}$ & & \\
\hline Total Adj. $R^{2}$ & .12 & & \\
\hline$R$ & $.41^{* *}$ & & \\
\hline 95\% Confidence limits from 0.04 to 0.30 & & & \\
\hline
\end{tabular}

correlation between dyadic sexual communication and total sexual functioning scores was significant, uniquely explaining $5 \%$ of the variance. The size and direction of the standardized regression coefficient suggests that higher levels of sexual functioning for women PPWC is associated with higher levels of dyadic sexual communication. For the men PPWC sample, the full regression model significantly explained $18 \%$ of the variance in total sexual functioning scores, $F(3,50)=4.66, p=.006$, adj $R^{2}=.18,95 \%$ CI $[-4.28,36.94]$. Two predictors displayed significant semipartial correlations, suggesting that higher levels of sexual functioning in men PPWC
Table 12 Multiple regression analysis predicting CSFQ total sexual functioning scores from predictor variables by gender for Partners of People with Cancer (PPWC)

\begin{tabular}{|c|c|c|c|}
\hline \multirow[b]{2}{*}{ Variable } & \multicolumn{3}{|c|}{ Women } \\
\hline & B & $\beta$ & $s r^{2}$ (unique) \\
\hline Dyadic Adjustment Scale (DAS) & .20 & .08 & \\
\hline Dyadic Sexual Communication (DSCS) & $.20^{*}$ & .27 & .05 \\
\hline \multicolumn{4}{|l|}{ Silencing the Self Scale (STSS) } \\
\hline Care as self sacrifice & -.15 & -.14 & \\
\hline (Intercept) & 28.00 & & \\
\hline$R^{2}$ & $.13^{\mathrm{a}}$ & & \\
\hline Total Adj. $R^{2}$ & .09 & & \\
\hline$R$ & $.36^{*}$ & & \\
\hline \multicolumn{4}{|l|}{$95 \%$ Confidence limits from 0.14 to 0.28} \\
\hline & & Men & \\
\hline SF12-Physical component summary & $.30^{*}$ & .35 & .11 \\
\hline Dyadic Sexual Communication (DSCS) & $.25^{*}$ & .36 & .11 \\
\hline \multicolumn{4}{|l|}{ Silencing the Self Scale (STSS) } \\
\hline Silencing the self & .03 & .04 & \\
\hline (Intercept) & 16.33 & & \\
\hline$R^{2}$ & $.23^{b}$ & & \\
\hline Total Adj. $R^{2}$ & .18 & & \\
\hline$R$ & $.48^{* *}$ & & \\
\hline 95\% Confidence limits from 0.04 to 0.42 & & & \\
\hline
\end{tabular}

is uniquely associated with higher physical health related quality of life and dyadic sexual communication.

\section{Discussion}

This study documented changes in sexual functioning post-cancer for both individuals with cancer, and their partners, across sexual and non-sexual cancers, and demonstrated an association between sexual function and psychological distress, quality of life, sexual communication, and aspects of self-silencing, using a multivariate analyses. Our findings extend previous research examining psycho-social factors associated with sexual changes experienced after cancer, reinforcing, in particular, the importance of physical wellbeing and sexual communication in the context of relationships.

In contrast to previous research that focused on cancers that directly affect the sexual and reproductive organs, in the present study we examined a range of cancer types, finding that sexuality was rated as important, with changes to sexual activities and functioning reported, across sexual and non-sexual cancers. Indeed, individuals with a non-sexual cancer were more likely than those with a sexual cancer to rate sex as an important aspect of 
their lives. This refutes the belief of some health professionals working in cancer care that sexuality is primarily a matter of concern for individuals experiencing cancers that directly affect the sexual and reproductive organs [124]. It also suggests that information and supportive interventions developed to alleviate sexual difficulties and facilitate sexual renegotiation should be offered to individuals with both sexual and non-sexual cancers, rather than primarily focused on individuals with sexual and reproductive cancers, as is the case currently [125].

Changes to sexual functioning and sexual activities were reported by both women and men in the present study, across people with cancer and partners. This stands in contrast to the notion that sexual changes are primarily experienced by men with cancer [79], and are not an issue of concern for women and partners [126]. The majority of women and men who participated in the study reported reductions in sexual functioning, supporting previous research $[8,9,29,44,127]$. As the average length of time since diagnosis in the present study was five years, this supports the contention that sexual difficulties can be one of the most enduring effects of cancer diagnosis and treatment [4].

The inclusion of partners in the current study addressed the recognition that partners are often neglected in research on sexuality post-cancer $[101,103,128]$. Women partners reported reductions across all aspects of sexual functioning, including sexual frequency, interest, arousal, and orgasm, whereas men partners reported reductions in sexual frequency, arousal and orgasm. As the majority of participants were in a heterosexual relationship, this suggests that when a man has cancer, all aspects of sexual functioning are diminished for the woman partner. In contrast, for this sample, when a woman has cancer, her male partner may maintain sexual interest, but experience reduced functioning in other aspects of the sexual relationship. The question of whether this means that sexual changes are more problematic for men than for women partners is deserved of further investigation. It has previously been reported that women do not consider changes in sexual desire in their male partner with prostate cancer a major concern, as their primary focus is survival of their husband [126]. However, qualitative reports in the present study suggested that sexual changes were problematic for many women partners, as was also the case for male partners $[111,112,129]$. This suggests that the sexual concerns of partners, as well as those of people with cancer, should be part of the agenda of health professionals working in cancer care $[82,83]$.

Previous research has suggested that changes in sexual functioning are associated with reduced quality of life and psychological distress $[10,36,47,48,58,61]$, relationship satisfaction [36], and couple communication [82,83]. This was confirmed in the correlational analysis in the present study, where significant associations were found between sexual functioning and a range of psychological and relational variables. There were commonalities and differences across men and women, and across people with cancer and partners, in the strength of the associations between sexual functioning and psycho-social variables. This is reflected in the multivariate analysis, which examined the relative importance of each of the predictor variables.

The finding that the physical component of QoL was a significant unique predictor of sexual functioning for men and women with cancer, as well as male partners, suggests that physical wellbeing is an important determinant of sexual wellbeing after cancer. Deterioration in physical wellbeing may be associated with cancer treatment in the case of men and women with cancer $[11,12]$. The physical consequences of aging may also be a factor affecting physical QOL and sexual functioning, suggested by previous reports that sexual frequency and functioning declines with age for some individuals $[130,131]$. However, the majority of participants in the present study described sexuality as an important aspect of their life and relationship, supporting previous reports that many late middle aged and older adults are sexually interested and active [132,133]. This refutes the widely held social construction that older adults are not interested in sex [134], a construction adopted by some health professionals working in cancer care [124,135], and suggests that information and support for sexual difficulties experienced after cancer should be offered to patients and their partners regardless of age.

In addition to physical QoL, for women with cancer, depression and mental QoL were unique predictors of sexual function. The association between psychological distress and sexual functioning is well documented, for both women and men in the general population $[136,137]$, with a bi-directional relationship existing between distress and sexual difficulties, with both potentially sharing a common etiology [138]. The gender difference in psychological predictors of sexual functioning found in the present study may reflect the lower levels of mental QoL reported by women with cancer in comparison to men. However, women did not report significantly higher rates of depression than men, the other unique predictor, and whilst they did report higher rates of anxiety, reflecting gender differences in anxiety in the general population [139], this was not a significant predictor of sexual functioning. It has previously been reported that marital satisfaction is associated with sexual functioning [140] and that women are more likely report marital dissatisfaction than men, which is associated with depression [141]. In the present study, relationship satisfaction was significantly correlated with a greater number of sexual functioning subscales for women than for men, suggesting that relationship satisfaction may be a factor in gender differences 
in psychological distress and sexual functioning after cancer. Gender differences in the relationship between psychological distress, QoL, sexual functioning and relationship satisfaction in the context of cancer are deserved of further examination.

Previous research has demonstrated an association between couple communication and adjustment in the context of cancer $[86,87,91,142]$. Couples who are mutually responsive, attend to each other's needs, and talk openly about their stress, are more able to engage in effective coping [87], which allows them to find benefits in the cancer experience, such as personal growth and relationship closeness $[88,89]$. This pattern of mutual communication has also been found to be associated with lower levels of distress for patients and partners, and higher levels of marital satisfaction $[86,143,144]$. In the present study, sexual communication was a significant predictor of sexual functioning for women with cancer, and for men and women partners, with higher levels of communication associated with higher levels of functioning. This supports the findings of a previous study conducted with men who had prostate cancer and their partners [39], and suggests that talking about sexual changes and concerns can play a major part in addressing difficulties. In this vein, in previous qualitative research conducted with partners of a person with cancer, sexual communication was identified as a key factor in sexual re-negotiation, allowing couples to discuss alternative forms of sexual intimacy in the face of physical changes experienced after cancer [82,107]. The importance of sexual communication in overcoming sexual difficulties and developing new sexual practices was also identified in accounts of men and women with cancer, and partners, in the qualitative component of the present study [113]. These findings reinforce the importance of recognizing the inter-subjective nature of sexual difficulties experienced after cancer, and the importance of researchers and clinicians adopting a relational approach $[88,145,146]$, including the development of couple-based information and support for sexual difficulties [147].

In the present study, sexual communication was not a significant predictor of sexual functioning for men with cancer in the multivariate analysis, even though significant associations were found in the correlation analysis between sexual communication, sexual desire and pleasure. In the general population, there is evidence that women are more likely than men to discuss sexual health concerns [148], and that absence of relationship communication on the part of male partners causes greater distress for women [149]. It has also been suggested that women's wellbeing is more strongly associated with relational factors than men's $[150,151]$. However, sexual communication was a predictor of sexual functioning for male partners in the present study, suggesting that there is an interaction between gender, the role of patient/partner, sexual functioning and sexual communication. The nature and implications of this interaction is deserved of further investigation.

Relational factors are also implicated in the finding that the 'care as self-sacrifice' subscale of self-silencing was a unique predictor of sexual functioning in men with cancer, with lower care as self-sacrifice associated with higher levels of functioning. In contrast to previous research examining self-silencing and psychological distress in cancer carers [98], there was no difference between men and women partners on levels of self-silencing in the present study. However, men with cancer reported significantly higher levels of 'care as self-sacrifice' and 'silencing the self' than women with cancer, in line with previous reports $[96,97,152]$. The 'care as self-sacrifice' subscale, the unique predictor of sexual functioning in the multivariate analysis, assesses the propensity to put the needs of others before the self. This suggests that men who put their partner's needs first report lower sexual functioning. Reports from the qualitative aspect of the present study [114], as well as previous research on women with cancer [153] and women partners [82], suggests that some women are engaging in coital sex in order to please their partner, rather than to fulfill their own needs, even when coital sex results in pain or discomfort. Men who are attuned to the woman's absence of desire or response may be less likely to initiate sex, and therefore to report lowered sexual functioning. However, relational closeness may be maintained through non-coital practices, as evidenced in the qualitative findings resulting from the present study [113], suggesting that lowered sexual functioning as measured by a standardized scale may not be a wholly negative experience. This suggests that researchers and clinicians need to be aware of the meaning of sexual functioning for men and women affected by cancer, and the way in which this meaning is negotiated in the context of relationships.

\section{Conclusions}

The strengths in the present study were the inclusion in the participant sample of sexual and non-sexual cancers, men and women, and people with cancer and partners, across a range of relationship contexts. The utilization of a range of standardized measures to evaluate sexual functioning, psychological distress, and relationship satisfaction and communication is also a strength. A limitation was the cross sectional nature of the study, which did not facilitate examination of changes over time, and the self-selected nature of the sample, potentially excluding individuals for whom sexual changes after cancer were not evident, or were not a concern. A further limitation was the greater proportion of women with breast cancer in the sample, compared to other cancer types. 
This was the result of the positive response to requests to take part in the research on the part of women with breast cancer, which may reflect the greater willingness of women to talk about sexual difficulties combined with the impact of breast cancer on women's sexuality $[8,15]$. However, we also received a good response from individuals and their partners affected by other types of cancer, including those with prostate, hematological, gastrointestinal, neurological, skin, respiratory, and head and neck cancers, substantiating our conclusion that sexual changes are experienced by individuals across a range of cancer types, and that relationship context is an important predictor of sexual functioning. This suggests that clinicians and researchers need to acknowledge the psycho-social context when dealing with sexual changes experienced after cancer, alongside physical wellbeing, across the whole spectrum of cancer care.

Changes in sexual activities and sexual functioning may be one of the most enduring negative effects of cancer treatments [5], but distress associated with such changes can be alleviated, and strategies of sexual renegotiation developed [113], through the provision of information and professional support. However, there is evidence that discussion of the nature and causes of sexual changes after cancer, as well provision of information about effective coping strategies, is often absent in clinical consultations $[124,135]$, in particular for women and for individuals with a non-sexual cancer [135]. As a result, sexual concerns remain unaddressed [154]. Equally, whilst a range of one-to-one and couple interventions have been developed to address sexual difficulties after cancer [125,155-158], these are primarily focused on the functioning of the body for individuals with breast, prostate or gynaecological cancer. The findings of the present study suggest that there needs to be an expansion of such support into non-sexual cancers. Details of specific strategies that can be adopted in raising sexual issues in a clinical context are now widely available [159-162]; these need to be utilised as part of normal clinical practice, with both patients and their partners, across all types of cancer. One example is the PLISSIT model of providing permission, limited information, specific suggestions, and intensive therapy [163]. This model facilitates various levels of intervention, as deemed appropriate for the patient and their partner: at the most basic level legitimating the discussion of sex and intimacy within couple relationships and with health professionals ("permission"); providing "limited information" through discussion or written information; "specific suggestions" about changes to sexuality following cancer; followed by referral for "intensive therapy" if needed. At the same time, information and checklists provided to people with cancer can facilitate their raising the subject of sexuality with clinicians, which can alleviate concerns that such discussion is unwanted e.g. $[164,165]$.

\section{Competing interests}

The authors declare that they have no competing interests.

\section{Authors' contributions}

JP, JMU and EG designed, planned and coordinated the study with significant input from The Australian Cancer and Sexuality Study Team (ACSST) ${ }^{1}$. JP performed the analysis and initial interpretation of the results with JU assisting in the interpretation of data. JMU and JP drafted the manuscript with EG revising it critically for important intellectual content. All authors read and approved the final manuscript.

${ }^{1}$ ACSST members include: Gerard Wain (Westmead Hospital), Gill Batt (Cancer Council New South Wales), Kendra Sundquist (Cancer Council New South Wales), Kim Hobbs (Westmead Hospital), Catherine Mason (Nepean Hospital), Laura Kirsten (Nepean Hospital) and Sue Carrick (National Breast Cancer Foundation).

\section{Acknowledgements}

An Australian Research Council Linkage Grant, LP0883344, funded this research in conjunction with the Cancer Council New South Wales and the National Breast Cancer Foundation. We received in-kind support from Westmead Hospital and Nepean Hospital. The chief investigators on the project were Jane Ussher, Janette Perz and Emilee Gilbert and the partner investigators were Gerard Wain, Gill Batt, Kendra Sundquist, Kim Hobbs, Catherine Mason, Laura Kirsten and Sue Carrick. We thank Tim Wong, Caroline Joyce, Emma Hurst, Jennifer Read, Anneke Wray, Jan Marie and Chloe Parton for research support and assistance.

Received: 29 January 2014 Accepted: 17 March 2014

Published: 28 March 2014

\section{References}

1. Hodges $\sqcup$, Humphris GM, Macfarlane G: A meta-analytic investigation of the relationship between the psychological distress of cancer patients and their carers. Soc Sci Med 2005, 60(1):1-12.

2. World Health Organisation: The world health organisation quality of life assessment (whoqol) position paper. Soc Sci Med 1995, 41:1403-1409.

3. Arrington R, Cofrancesco J, Wu AW: Questionnaires to measure sexual quality of life. Qual Life Res 2004, 13(10):1643-1658.

4. Anderson BL, Golden-Kreutz DM, Baider L, Cooper CL, De-Nour AK: Sexual self-concept for the women with cancer. In Cancer and the Family. England: John Wiley and Sons; 2000.

5. De Groot JM, Mah K, Fyles A, Winton S, Greenwood S, De Petrillo AD, Devins S: The psychosocial impact of cervical cancer among affected women and their partners. Int J Gynecol Cancer 2005, 15:918-925.

6. Bertero C, Wilmoth MC: Breast cancer diagnosis and its treatment affecting the self. Cancer Nurs 2007, 30(3):194-202.

7. Andersen BL: In sickness and in health: Maintaining intimacy after breast cancer recurrence. Cancer J 2009, 15(1):70-73.

8. Gilbert E, Ussher JM, Perz J: Sexuality after breast cancer: a review. Maturitas 2010, 66:397-407.

9. Gilbert E, Ussher JM, Perz J: Sexuality after gynaecological cancer: a review of the material, intrapsychic, and discursive aspects of treatment on women's sexual-wellbeing. Maturitas 2011, 70(1):42-57.

10. Howlett K, Koetters T, Edrington J, West C, Paul S, Lee K, Aouizerat BE, Wara W Swift $P$, Miaskowski $C$ : Changes in sexual function on mood and quality of life in patients undergoing radiation therapy for prostate cancer. Oncol Nurs Forum 2010, 37(1):E58-E66.

11. Ascencio M, Blank T, Descartes $L$, Crawford $A$ : The prospect of prostate cancer: a challenge for gay men's sexuality as they age. Sex Res Soc Pol 2009, 6(4):38-51.

12. Carter J, Stabile C, Gunn A, Sonoda Y: The physical consequences of gynecologic cancer surgery and their impact on sexual, emotional, and quality of life issues. J Sex Med 2013, 10:21-34.

13. Basson R: Sexual function of women with chronic illness and cancer. Womens Health 2010, 6(3):407-429.

14. Holmes L: Sexuality in gynaecological cancer patients. Canc Nurs Pract 2005, 4(6):35-39.

15. Ussher JM, Perz J, Gilbert E: Changes to sexual well-being and intimacy after breast cancer. Cancer Nurs 2012, 35(6):456-464.

16. Bergmark K, Avall-Lundqvist E, Dickman PW, Henningsohn L, Steineck G: Vaginal changes and sexuality in women with a history of cervical cancer. N Engl J Med 1999, 340(18):1383-1389. 
17. Safarinejad MR, Shafiei N, Safarinejad S: Quality of life and sexual functioning in young women with early stage breast cancer 1 year after lumpectomy. Psycho Oncol 2013, 22(6):1242-1248.

18. Stead ML, Fallowfield L, Selby P, Brown JM: Psychosexual function and impact of gynaecological cancer. Best Pract Res Clin Obstet Gynaecol 2007, 21(2):309-320.

19. Lamb MA, Sheldon TA: The sexual adaptation of women treated for endometrial cancer. Cancer Pract 1994, 2(2):103-113.

20. Plotti F, Sansone M, Di Donato V, Antonelli E, Altavilla T, Angioli R, Panici PB: Quality of life and sexual function after type C2/type III radical hysterectomy for locally advanced cervical cancer: a prospective study. J Sex Med 2011, 8(3):894-904.

21. Fobair P, Stewart SL, Chang S, D'Onofrio C, Banks PJ, Bloom JR: Body image and sexual problems in young women with breast cancer. Psychooncology 2006, 15(7):579-594.

22. Archibald S, Lemieux S, Byers ES, Tamlyn K, Worth J: Chemically-induced menopause and the sexual functioning of breast cancer survivors. Women Ther 2006, 29(1/2):83-106.

23. Wilmoth MC: The aftermath of breast cancer: an altered sexual self. Cancer Nurs 2001, 24(4):278-286.

24. Sekse RJT, Raaheim M, Blaaka G, Gjengedal E: Life beyond cancer: women's experiences 5 years after treatment for gynaecological cancer. Scand J Caring Sci 2010, 24(4):799-807.

25. Bal MD, Yilmaz SD, Beji NK: Sexual health in patients with gynecological cancer: a qualitative study. Sex Disabil 2013, 31(1):83-92.

26. Weijmar Schultz WCM, Van De Wiel HBM, Bouma J: Psychosexual functioning after treatment for cancer of the cervix: a comparative and longitudinal study. Int J Gynecol Cancer 1991, 1(1):37-46.

27. Andersen $B L$, Hacker NF: Psychosexual adjustment after vulvar surgery. Obstet Gynecol 1983, 62(4):457-462.

28. Green MS, Naumann RW, Elliot M, Hall JB, Higgins RV, Grigsby JH: Sexual dysfunction following vulvectomy. Gynecol Oncol 2000, 77(1):73-77.

29. Meyerowitz B, Desmond K, Rowland J, Wyatt G, Ganz P: In Sexuality following breast cancer, Journal of Sex and Marital Therapy, Volume 25; 1999:237-250

30. Juraskova I, Butow P, Bonner C, Robertson R, Sharpe L: Sexual adjustment following early stage cervical and endometrial cancer: prospective controlled multi-centre study. Psycho Oncol 2013, 22(1):153-159.

31. Daniel A, Haddovv S: Erectile dysfunction after prostate cancer. Clinical Advisor 2011, 14(3):64-68

32. Jankowska M: Sexual functioning of testicular cancer survivors and their partners: a review of the literature. Rep Pract Oncol Radiother 2012, 17:54-62.

33. Higano CS: Sexuality and intimacy after definitive treatment and subsequent androgen deprivation therapy for prostate cancer. J Clin Oncol 2012, 30(30):3720-3725.

34. Sanders S, Pedro LW, Bantum E, Galbraith M: Couples surviving prostate cancer: long-term intimacy needs and concerns following treatment. Clin J Oncol Nurs 2006, 10(4):503-508.

35. Arrington Ml: Prostate cancer and the social construction of masculine sexual identity. Int J Mens Health 2008, 7(3):299-306.

36. Galbraith ME, Arechiga A, Ramirez J, Pedro LW: Prostate cancer survivors' and partners' self-reports of health-related quality of life, treatment symptoms, and marital satisfaction $2.5-5.5$ years after treatment. Oncol Nurs Forum 2005, 32(2):E30-E41.

37. Navon L, Morag M: Advanced prostate cancer patients' ways of coping with the hormone therapy's affect on body, sexuality, and spousal ties. Qual Health Res 2003, 13:1378-1391.

38. Bokhour BG, Clark JA, Inui TS, Silliman RA, Talcott JA: Sexuality after treatment for early prostate cancer: exploring the meanings of "erectile dysfunction". J Gen Intern Med 2001, 16:649-655.

39. Badr H, Carmack Taylor CL: Sexual dysfunction and spousal communication in couples coping with prostate cancer. Psycho Oncol 2009, 18(7):735-746.

40. Dahn JR, Penedo FJ, Gonzalez JS, Esquiabro M, Antoni MH, Roos BA Schneiderman N: Sexual functioning and quality of life after prostate cancer treatment: considering sexual desire. Urology 2004, 63(2):273-277.

41. Carpentier MY, Fortenberry JD: Romantic and sexual relationships, body image, and fertility in adolescent and young adult testicular cancer survivors: a review of the literature. J Adolesc Health 2010, 47(2):115-125.
42. Tuinman MA, Hoekstra HJ, Vidrine DJ, Gritz ER, Sleijfer DT, Fleer J, HoekstraWeebers J: Sexual function, depressive symptoms and marital status in nonseminoma testicular cancer patients: a longitudinal study. Psycho Oncol 2010, 19(3):238-247.

43. Gurevich M, Bishop S, Bower J, Malka M, Nyhof-Young J: (Dis)embodying gender and sexuality in testicular cancer. Soc Sci Med 2004, 58(9):1597-1607.

44. Rossen P, Pedersen AF, Zachariae R, von der Maase H: Sexuality and body image in long-term survivors of testicular cancer. Eur J Cancer 2012, 48(4):571-578.

45. Tsay-Yi A, Zauszniewski JA, King TM: Demographics, cancer-related factors, and sexual function in rectal cancer patients in taiwan: preliminary findings. Cancer Nurs 2012, 35(5):E17-E22.

46. Panjari M, Bell RJ, Burney S, Bell S, McMurrick PJ, Davis SR: Sexual function, incontinence, and wellbeing in women after rectal cancer-a review of the evidence. J Sex Med 2012, 9(11):2749-2758.

47. Milbury K, Cohen L, Jenkins R, Skibber JM, Schover LR: The association between psychosocial and medical factors with long-term sexual dysfunction after treatment for colorectal cancer. Support Care Cancer 2013, 21(3):793-802.

48. Traa MJ, De Vries J, Roukema JA, Den Oudsten BL: Sexual (dys)function and the quality of sexual life in patients with colorectal cancer: a systematic review. Ann Oncol 2012, 23(1):19-27.

49. Donovan KA, Thompson LM, Hoffe SM: Sexual function in colorectal cancer survivors. Cancer Control 2010, 17(1):44-51.

50. van der Horst-Schrivers ANA, leperen EV, Wymenga ANM, Boezen HM, Weijmar-Schultz W, Kema IP, Meijer WG, Herder WWD, Willemse PHB, Links TP, De Vries E: Sexual function in patients with metastatic midgut carcinoid tumours. Neuroendocrinology 2009, 89(2):231-236.

51. Low C, Fullarton M, Parkinson E, O'Brien K, Jackson SR, Lowe D, Rogers SN: Issues of intimacy and sexual dysfunction following major head and neck cancer treatment. Oral Oncol 2009, 45(10):898-903.

52. Monga U, Tan G, Ostermann HJ, Monga TN: Sexuality in head and neck cancer patients. Arch Phys Med Rehabil 1997, 78(3):298-304.

53. Salem HK: Radical cystectomy with preservation of sexual function and fertility in patients with transitional cell carcinoma of the bladder: new technique. Int J Urol 2007, 14:294-298.

54. Jonker-Pool G, Hoekstra HJ, van Imhoff GW, Sonneveld DJA, Sleijfer DT, van Driel MF, Koops HS, van de Wiel HBM: Male sexuality after cancer treatment-needs for information and support: testicular cancer compared to malignant lymphoma. Patient Educ Couns 2004, 52(2):143-150.

55. Jarden M, Schjodt I, Thygesen $\mathrm{KH}$ : The impact of hematopoietic stem cell transplantation on sexuality: a systematic review of the literature. Bone Marrow Transplant 2012, 47:716+.

56. Shell JA, Carolan M, Zhang Y, Meneses KD: The longitudinal effects of cancer treatment on sexuality in individuals with lung cancer. Oncol Nurs Forum 2008, 35(1):73-79.

57. Galbraith ME, Crighton F: Alterations of sexual function in men with cancer. Semin Oncol Nurs 2008, 24(2):102-114.

58. Greenfield DM, Walters SJ, Coleman RE, Hancock BW, Snowden JA, Shalet SM, DeRogatis LR, Ross RJM: Quality of life, self-esteem, fatigue, and sexual function in young men after cancer: a controlled cross-sectional study. Cancer 2010, 116(6):1592-1601.

59. Bober SL, Zhou ES, Chen B, Manley PE, Kenney LB, Recklitis CJ: Sexual function in childhood cancer survivors: a report from project REACH. J Sex Med 2013, 10(8):2084-2093.

60. Zebrack BJ, Foley S, Wittmann D, Leonard M: Sexual functioning in young adult survivors of childhood cancer. Psycho Oncol 2010, 19(8):814-822.

61. Frumovitz $M$, Sun CC, Schover LR, Munsell MF, Jhingran A, Wharton JT, Eifel P, Bevers TB, Levenback CF, Gershenson DM, Bodurka DC: Quality of life and sexual functioning in cervical cancer survivors. J Clin Oncol 2005, 23(30):7428-7436.

62. Punnen S, Cowan JE, Dunn LB, Shumay DM, Carroll PR, Cooperberg MR: A longitudinal study of anxiety, depression and distress as predictors of sexual and urinary quality of life in men with prostate cancer. $B J U$ Int 2013, 112(2):E67-E75.

63. Namiki S, Ishidoya S, Nakagawa H, Ito A, Kaiho Y, Tochigi T, Takegami M, Arai $Y$ : The relationships between preoperative sexual desire and quality of life following radical prostatectomy: a 5-year follow-Up study. J Sex Med 2012, 9(9):2448-2456. 
64. Kimura M, Bañez LL, Schroeck FR, Gerber L, Qi J, Satoh T, Baba S, Robertson CN, Walther PJ, Donatucci CF, Moul JW, Polascik TJ: Factors predicting early and late phase decline of sexual health-related quality of life following radical prostatectomy. J Sex Med 2011, 8(10):2935-2943.

65. Kiserud CE, Schover LR, Dahl AA, Fosså A, Bjøro T, Loge JH, Holte H, Yuan Y, Fosså SD: Do male lymphoma survivors have impaired sexual function? J Clin Oncol 2009, 27(35):6019-6026.

66. Arden-Close $E_{1}$ Eiser $C$, Pacey A: Sexual functioning in male survivors of lymphoma: a systematic review (CME). J Sex Med 2011, 8(7):1833-1840.

67. Kim KR, Chung HC, Lee E, Kim SJ, Namkoong K: Body image, sexual function and depression in Korean patients with breast cancer: modification by 5-HTT polymorphism. Support Care Cancer 2012, 20(9):2177-2182

68. Den Oudsten BL, Van Heck GL, Van der Steeg AFW, Roukema JA, De Vries J: Clinical factors are not the best predictors of quality of sexual life and sexual functioning in women with early stage breast cancer. In PsychoOncology, Volume 19. US: John Wiley \& Sons; 2010:646-656.

69. Greimel ER, Winter R, Kapp KS, Haas J: Quality of life and sexual functioning after cervical cancer treatment: a long-term follow-up study. Psycho Oncol 2009, 18(5):476-482.

70. Fernandes W, Kimura M: Health related quality of life of women with cervical cancer. Rev Lat-Am Enferm 2010, 18(3):360-367.

71. Matthews AK, Aikens JE, Helmrich SP, Anderson DD, Herbst AL, Waggoner SE: Sexual functioning and mood among long-term survivors of clear-cell adenocarcinoma of the vagina or cervix. J Psychosoc Oncol 2000, 17(3-4):27-45

72. Rouanne M, Massard C, Hollebecque A, Rousseau V, Varga A, Gazzah A Neuzillet $Y$, Lebret T, Soria J-C: Evaluation of sexuality, health-related quality-of-life and depression in advanced cancer patients: a prospective study in a Phase I clinical trial unit of predominantly targeted anticancer drugs. Eur J Cancer 2013, 49(2):431-438.

73. Biglia N, Moggio G, Peano E, Sgandurra P, Ponzone R, Nappi RE, Sismondi $P$ : Effects of surgical and adjuvant therapies for breast cancer on sexuality, cognitive functions, and body weight. I Sex Med 2010, 7(5):1891-1900

74. Orsini RG, Thong MSY, van de Poll-Franse LV, Slooter GD, Nieuwenhuiizen GAP, Rutten HJT, de Hingh IHJT: Quality of life of older rectal cancer patients is not impaired by a permanent stoma. Eur J Surg Oncol 2013, 39(2):164-170.

75. Grant M, McMullen CK, Altschuler A, Mohler MJ, Hornbrook MC, Herrinton LJ, Wendel CS, Baldwin CM, Krouse RS: Gender differences in quality of life among long-term colorectal cancer survivors with ostomies. Oncol Nurs Forum 2011, 38(5):587-596

76. Zeng YC, Li D, Loke AY: Life after cervical cancer: quality of life among chinese women. Nurs Health Sci 2011, 13(3):296-302

77. Jenkins R, Schover LR, Fouladi RT, Warneke C, Neese L, Klein EA, Zippe C, Kupelian P: Sexuality and health-related quality of life after prostate cancer in African-American and white men treated for localized disease. J Sex Marital Ther 2004, 30(2):79-93.

78. Manganiello A, Hoga LAK, Reberte LM, Miranda CM, Rocha CAM: Sexuality and quality of life of breast cancer patients post mastectomy. Eur J Oncol Nurs 2011, 15(2):167-172

79. Traa MJ, Orsini RG, Oudsten BLD, Vries JD, Roukema JA, Bosman SJ, Dudink RL, Rutten HJT: Measuring the health-related quality of life and sexual functioning of patients with rectal cancer: Does type of treatment matter? Int J Cancer 2014, 134(4):979-987.

80. Kleinplatz PJ (Ed): New directions in sex therapy: Innovations and alternatives. 2nd edition. Philadelphia, PA, US: Brunner-Routledge; 2012.

81. Alder J, Zanetti R, Wight E, Urech C, Fink N, Bitzer J: Sexual dysfunction after premenopausal stage I and II breast cancer: Do androgens play a role? J Sex Med 2008, 5:1898-1906.

82. Hawkins Y, Ussher JM, Gilbert E, Perz J, Sandoval M, Sundquist K: Changes in sexuality and intimacy after the diagnosis of cancer. The experience of partners in a sexual relationship with a person with cancer. Cancer Nurs 2009, 34(4):271-280

83. Gilbert E, Ussher JM, Perz J: Renegotiating sexuality and intimacy in the context of cancer: the experiences of carers. Arch Sex Behav 2010, 39(4):998-1009.

84. Aerts L, Enzlin P, Vergote I, Verhaeghe J, Poppe W, Amant F: Sexual, psychological, and relational functioning in women after surgical treatment for vulvar malignancy: a literature review. J Sex Med 2012, 9(2):361-371.
85. Manne S, Ostroff J, Norton T, Fox K, Goldstein L, Grana G: Cancer-related relationship communication in couples with early stage breast cancer. Psycho Oncol 2006, 15(3):234-247.

86. Badr H, Acitelli L, Carmack Taylor CL: Does talking about their relationship affect couples' marital and psychological adjustment to lung cancer? J Cancer Surviv 2008, 2(1):53-64

87. Zunkel G: Relational coping processes: couples' response to a diagnosis of early stage breast cancer. J Psychosoc Oncol 2002, 20(4):39-55.

88. Kayser K, Watson LE, Andrade JT: Cancer as a "we-disease": examining the process of coping from a relational perspective. Fam Syst Health 2007, 25(4):404-418.

89. Manne S, Ostroff J, Winkel G, Goldstein L, Fox K, Grana G: Posttraumatic growth after breast cancer: patient, partner, and couple perspectives. Psychosom Med 2004, 66(3):442-454.

90. Kuijer RG, Ybema JF, Buunk BP, de Jong GM, Thijs-boer F, Sanderman R: Active engagement, protective buffering and overprotection: three ways of giving support by intimate partners of patients with cancer. J Soc Clin Psychol 2000, 19(2):256-275

91. Badr H, Carmack Taylor CL: Social constraints and spousal communication in lung cancer. Psycho Oncol 2006, 15(8):673-683.

92. Jack DC: Silencing the self: Women and depression. Cambridge MA: Harvard University Press; 1991.

93. Carr JG, Gilroy FD, Sherman MF: Silencing the self and depression among women. Psychol Women Q 1996, 20:375-392.

94. Cowan G, Bommersbach M, Curtis S: Codependency, loss of self and power. Psychol Women Q 1995, 19:221-236.

95. Jack DC, Dill D: The silencing the self scale: schemas of intimacy with depression in women. Psychol Women Q 1992, 16:97-106.

96. Whiffen VE, Foot ML, Thompson JM: Self-silencing mediates the link between marital conflict and depression. J Soc Pers Relat 2007, 24(6):993-1006.

97. Cramer KM, Thoms N: Factor structure of the silencing the self scale in women and men. pers Indiv Differ 2003, 35:525-535.

98. Ussher JM, Perz J: Gender differences in self-silencing and psychological distress in informal cancer carers. Psychol Women Q 2010, 34(2):228-242.

99. Remen AL, Chambless DL, Rodebaugh TL: Gender differences in the construct validity of the silencing the self scale. Psychol Women Q 2002, 26:151-159.

100. Duarte LM, Thompson JM: Sex-differences in self-silencing. Psychol Rep 1999, 85:145-161.

101. Reichers EA: Including partners into the diagnosis of prostate cancer: a review of the literature to provide a model of care. Urol Nurs 2004, 24(1):22-38

102. Harden J, Schafenacker A, Northouse L, Mood D, Pienta K, Hussain M, Baranowski K: Couples' experience with prostate cancer: a focus group. Oncol Nurs Forum 2002, 29(4):701-709.

103. O'Shaughnessy PK, Ireland C, Pelentsov LT, Laws A, Esterman AJ: Impaired sexual function and prostate cancer: a mixed method investigation into the experiences of men and their partners. J Clin Nurs 2013, 22(23-24):3492-3502.

104. Maltaris T, Weigel M, Dittrich R: Cancer and fertility preservation in females: where we stand and where we are heading. Exp Rev Endocrinol Metab 2009, 4(1):79-89.

105. Soothill K, Morris SM, Thomas C, Harman JC, Francis B, Mclllmurray MB: The universal, situational, and personal needs of cancer patients and their main carers. Eur J Oncol Nurs 2003, 7(1):5-16.

106. Maughan K, Heyman B, Matthews M: In the shadow of risk: how men cope with a partners gynaecological cancer. Int J Nurs Stud 2002, 39:27-34.

107. Gilbert E, Ussher JM, Hawkins Y: Accounts of disruptions to sexuality following cancer: the perspective of informal carers who are partners of a person with cancer. Health 2009, 13(5):523-541.

108. Hannah P, Adams D, Lee A, Glover V: Links between early post-partum mood and post-natal depression. Br J Psychiatry Suppl 1992, 160:777-780.

109. Yiou R, Ebrahiminia V, Mouracade P, Lingombet O, Abbou C: Sexual quality of life in women partnered with men using intracavernous alprostadil injections after radical prostatectomy. J Sex Med 2013, 10(5):1355-1362.

110. Perz J, Ussher JM, Gilbert E: Constructions of sex and intimacy after cancer: Q methodology study of people with cancer, their partners, and health professionals. BMC Cancer 2013, 13:270. 
111. Gilbert E, Ussher JM, Perz J: Embodying sexual subjectivity after cancer: A qualitative study of people with cancer and intimate partners. Psychol Health 2013, 28(6):603-619.

112. Gilbert E, Ussher JM, Perz J, Wong WKT, Hobbs K, Mason C: Men's experiences of sexuality after cancer: a material discursive intra-psychic approach. Cult Health Sex 2013, 15(8):881-895.

113. Ussher JM, Perz J, Gilbert E, Wong WKT, Hobbs K: Renegotiating sex after cancer: resisting the coital imperative. Cancer Nurs 2013, 36(6):454-462.

114. Ussher JM, Perz J, Gilbert E: Women's sexuality after cancer: a qualitative analysis of sexual changes and renegotiation. Women Ther: in press.

115. Keller A, McGarvey EL, Clayton AH: Reliability and construct validity of the changes in sexual functioning questionnaire short-form (CSFQ-14). J Sex Marital Ther 2006, 32(1):43-52.

116. Zigmond AS, Snaith RP: The hospital anxiety and depression scale. Acta Psychiatr Scand 1983, 67(6):361-370

117. Bjelland I, Dahl AA, Haug TT, Neckelmann D: The validity of the hospital anxiety and depression scale. An updated literature review. $J$ Psychosom Res 2002, 52:69-77.

118. Ware JEJ, Kosinski M, Keller SD: A 12-item short-form health survey. Med Care 1996, 24:220-233.

119. Resnick B, Partker R: Simplified scoring and psychometrics of the revised 12-item Short-Form Health Survey. Outcomes Manag Nurs Pract 2001, 5(4):161-166.

120. Sabourin S, Valois $P$, Lussier Y: Development and validation of a brief version of the dyadic adjustment scale with a nonparametric item analysis model. Psychol Assess 2005, 17(1):15-27.

121. Sharpley CF, Rogers HJ: Preliminary validation of the abbreviated spanier dyadic adjustment scale: some psychometric data regarding a screening test of marital adjustment. Educ Psychol Meas 1984, 44(4):1045-1049.

122. Catania J: Dyadic sexual communication scale. In Handbook of SexualityRelated Measures. Edited by Davis M. London: Sage; 1998

123. Tabachnick BG, Fidell LS: Using Multivariate Statistics. Boston: Pearson; 2013.

124. Hordern AJ, Street AF: Communicating about patient sexuality and intimacy after cancer: mismatched expectations and unmet needs. Med J Aust 2007, 186(5):224-227.

125. Miles C, Candy B, Jones L, Williams R, Tookman A, King M: Interventions for sexual dysfunction following treatments for cancer. Cochrane Database Syst Rev 2007, 4:CD005540.

126. Rivers BM, August EM, Gwede CK, Hart A, Donovan KA, Pow-Sang JM Quinn GP: Psychosocial issues related to sexual functioning among African-American prostate cancer survivors and their spouses. Psycho Oncol 2011, 20(1):106-110

127. Mercadante $S$, Vitrano V, Catania V: Sexual issues in early and late stage cancer: a review. Support Care Cancer 2010, 18(6):659-665.

128. Perez MA, Skinner EC, Meyerowtiz BE: Sexuality and intimacy following radical prostatectomy: patient and partner perspectives. Health Psychol 2002, 21(3):288-293.

129. Ussher JM, Perz J, Gilbert E: The experience and construction of changes to women's sexuality after breast cancer. In The essential handbook of women's sexuality, vol 2. Edited by Castaneda D. Santa Barbara: Praeger; 2013:171-196.

130. Koch PB, Mansfield PK: Women's sexuality as they age: the more things change, the more they stay the same. Siecus Report 2001, 30(2):5-9.

131. DeLamater JD, Sill M: Sexual desire in later life. J Sex Res 2005 42(2):138-149.

132. Gott M, Hinchliff S: How important is sex in later life? the views of older people. Soc Sci Med 2003, 56(8):1617-1628.

133. Loe M: Sex and the senior woman: pleasure and danger in the viagra era. Sexualities 2004, 7(3):303-326

134. Watters $Y$, Boyd TV: Sexuality in later life: opportunity for reflections for healthcare providers. Sex Relat Ther 2009, 24(3-4):307-315.

135. Ussher JM, Perz J, Gilbert E, Wong WKT, Mason C, Hobbs K, Kirsten L: Talking about sex after cancer: a discourse analytic study of health care professional accounts of sexual communication with patients. Psychol Health 2013, 28(12):1370-1390.

136. Kennedy SH, Dickens SE, Eisfeld BS, Bagby RM: Sexual dysfunction before antidepressant therapy in major depression. J Affect Disord 1999, 56(2-3):201-208.
137. Laurent SM, Simons AD: Sexual dysfunction in depression and anxiety: conceptualizing sexual dysfunction as part of an internalizing dimension. Clin Psychol Rev 2009, 29(7):573-585.

138. Hartmann U: Depression and sexual dysfunction. J Mens Health Gend 2007, 4(1):18-25

139. Australian Institute of Health and Welfare: Australia's Health 2012. In vol. Australia's Health series no.13. Cat. no. AUS 156. Canberra: AlHW; 2012

140. Trudel G, Goldfarb MR: Marital and sexual functioning and dysfunctioning, depression and anxiety. Sexologies 2010, 19(3):137-142

141. Goldfarb MR, Trudel G, Boyer R, Préville M: Marital relationship and psychological distress: its correlates and treatments. Sex Relat Ther 2007, 22(1):109-126.

142. Manne S, Badr H: In Intimacy processes and psychological distress among couples coping with head and neck or lung cancers, Psycho-Oncology, Volume 19. ; 2010:941-954

143. Lindau ST, Surawska H, Paice J, Baron SR: Communication about sexuality and intimacy in couples affected by lung cancer and their clinical-care providers. Psycho Oncol 2011, 20(2):179-185

144. Ptacek JT, Ptacek JJ, Dodge KL: Coping with breast cancer from the perspectives of husbands and wives. J Psychosoc Oncol 1994, 12(3):47-72.

145. Ussher JM, Wong WKT, Perz J: In A qualitative analysis of changes in relationship dynamics and roles between people with cancer and their primary informal carer, Health: An Interdisciplinary Journal, Volume 15; 2011:650-667.

146. Kayser K, Sormanti M, Strainchamps E: Women coping with cancer. Psychol Women Q 1999, 23(4):725-739.

147. Regan TW, Lambert SD, Girgis A, Kelly B, Kayser K, Turner J: Do couplebased interventions make a difference for couples affected by cancer?: a systematic review. BMC Cancer 2012, 12(1):279-292.

148. Emmers-Sommer T, Nebel S, Allison M-L, Cannella M, Cartmill D, Ewing S, Horvath D, Osborne J, Wojtaszek B: Patient-provider communication about sexual health: the relationship with gender, age, gender-stereotypical beliefs, and perceptions of communication inappropriateness. Sex Roles 2009, 60(9-10):669-681

149. Gottman JM, Krokoff $\sqcup:$ Marital interaction and satisfaction: a longitudinal view. J Consult Clin Psychol 1989, 57(1):47-52.

150. Jordan JV: The meaning of mutuality. In Women's Growth in Connection: Writings from the Stone Center. Edited by Kaplan AG, Miller JB, Stiver IP, Surrey JL. New York: Guilford; 1991:81-96.

151. Kaplan A: The "self-in-relation": implications for depression in women. Psychotherapy 1986, 23:234-242.

152. Gratch LB, Bassett ME, Attra SL: The relationship of gender and ethnicity to self silencing and depression among college students. Psychol Women $Q$ 1995, 19:509-519.

153. Jensen PT: Gynaecological cancer and sexual functioning: Does treatment modality have an impact? Sexologies 2007, 16:279-285.

154. Ussher JM, Perz J, Gilbert E: Information needs associated with changes to sexual well-being after breast cancer. J Adv Nurs 2013, 69(3):327-337.

155. Schover LR, Fouladi RT, Warneke CL, Neese L, Klein EA, Zippe C, Kupelian PA: Defining sexual outcomes after treatment for localized prostate carcinoma. Cancer 2002, 95(8):1773-1785.

156. Canada AL, Neese LE, Sui D, Schover LR: Pilot intervention to enhance sexual rehabilitation for couples after treatment for localized prostate carcinoma. Cancer 2005, 104(12):2689-2700.

157. Schover LR, Jenkins R, Sui D, Adams JH, Marion MS, Jackson KE: Randomized trial of peer counseling on reproductive health in African American breast cancer survivors. J Clin Oncol 2006, 24(10):1620-1626.

158. Latini DM, Hart SL, Coon DW, Knight SJ: Sexual rehabilitation after localized prostate cancer: current interventions and future directions. Cancer J 2009, 15:34-40.

159. Hordern AJ, Currow DC: A patient-centred approach to sexuality in the face of life-limiting illness. Med J Aust 2003, 179:s8-s11.

160. Brandenburg $U$, Bitzer J: The challenge of talking about sex: the importance of patient-physician interaction. Maturitas 2009, 63(2):124-127.

161. Hughes MK: Sexuality and the cancer survivor. A silent coexistence. Cancer Nurs 2000, 23(6):477-482.

162. Katz A: Do ask, do tell: why do so many nurses avoid the topic of sexuality? Am J Nurs 2005, 105(7):66-68. 
163. Annon JS: PLISSIT therapy. In Handbook of Innovative Psychotherapies. Edited by Corsine RJ. New York: Wiley and Sons; 1981:629-639.

164. Breast cancer and sexual wellbeing information booklet. http://www. bcna.org.au/sites/default/files/bcn_sexual_wellbeing_brochure_v.2.pdf.

165. Sexuality, intimacy and cancer: a self-help guide for people with cancer and their partner. http://www.uws.edu.au/_data/assets/pdf_file/0010/ 353494/Cancer_sex_no_trims.pdf.

doi:10.1186/1471-2407-14-228

Cite this article as: Perz et al:: Feeling well and talking about sex:

psycho-social predictors of sexual functioning after cancer. BMC Cancer 2014 14:228.

\section{Submit your next manuscript to BioMed Central and take full advantage of:}

- Convenient online submission

- Thorough peer review

- No space constraints or color figure charges

- Immediate publication on acceptance

- Inclusion in PubMed, CAS, Scopus and Google Scholar

- Research which is freely available for redistribution 